\title{
How consistent are top-down hydrocarbon emissions based on formaldehyde observations from GOME-2 and OMI?
}

\author{
T. Stavrakou ${ }^{1}$, J.-F. Müller ${ }^{1}$, M. Bauwens ${ }^{1}$, I. De Smedt ${ }^{1}$, M. Van Roozendael ${ }^{1}$, M. De Mazière ${ }^{1}$, C. Vigouroux ${ }^{1}$, \\ F. Hendrick ${ }^{1}$, M. George ${ }^{2}$, C. Clerbaux ${ }^{2,3}$, P.-F. Coheur ${ }^{3}$, and A. Guenther ${ }^{4}$ \\ ${ }^{1}$ Belgian Institute for Space Aeronomy, Avenue Circulaire 3, 1180, Brussels, Belgium \\ ${ }^{2}$ UPMC Univ. Paris 6; Université Versailles St.-Quentin; CNRS/INSU, LATMOS-IPSL, \\ 75252, CEDEX 05, Paris, France \\ ${ }^{3}$ Spectroscopie de l'Atmosphère, Service de Chimie Quantique et Photophysique, \\ Université Libre de Bruxelles, 1050, Brussels, Belgium \\ ${ }^{4}$ Atmospheric Sciences and Global Change Division, Pacific Northwest National Laboratory, \\ Richland, Washington State, USA
}

Correspondence to: T. Stavrakou (jenny@aeronomie.be)

Received: 19 March 2015 - Published in Atmos. Chem. Phys. Discuss.: 22 April 2015

Revised: 9 September 2015 - Accepted: 14 October 2015 - Published: 26 October 2015

\begin{abstract}
The vertical columns of formaldehyde (HCHO) retrieved from two satellite instruments, the Global Ozone Monitoring Instrument-2 (GOME-2) on Metop-A and the Ozone Monitoring Instrument (OMI) on Aura, are used to constrain global emissions of $\mathrm{HCHO}$ precursors from open fires, vegetation and human activities in the year 2010. To this end, the emissions are varied and optimized using the adjoint model technique in the IMAGESv2 global CTM (chemical transport model) on a monthly basis and at the model resolution. Given the different local overpass times of GOME2 (09:30 LT) and OMI (13:30 LT), the simulated diurnal cycle of HCHO columns is investigated and evaluated against ground-based optical measurements at seven sites in Europe, China and Africa. The modeled diurnal cycle exhibits large variability, reflecting competition between photochemistry and emission variations, with noon or early afternoon maxima at remote locations (oceans) and in regions dominated by anthropogenic emissions, late afternoon or evening maxima over fire scenes, and midday minima in isoprene-rich regions. The agreement between simulated and ground-based columns is generally better in summer (with a clear afternoon maximum at mid-latitude sites) than in winter, and the annually averaged ratio of afternoon to morning columns is slightly higher in the model (1.126) than in the ground-based measurements (1.043).
\end{abstract}

The anthropogenic VOC (volatile organic compound) sources are found to be weakly constrained by the inversions on the global scale, mainly owing to their generally minor contribution to the HCHO columns, except over strongly polluted regions, like China. The OMI-based inversion yields total flux estimates over China close to the bottom-up inven-

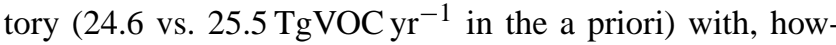
ever, pronounced increases in the northeast of China and reductions in the south. Lower fluxes are estimated based on

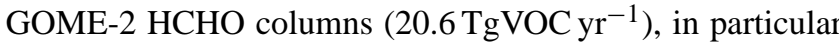
over the northeast, likely reflecting mismatches between the observed and the modeled diurnal cycle in this region.

The resulting biogenic and pyrogenic flux estimates from both optimizations generally show a good degree of consistency. A reduction of the global annual biogenic emissions of isoprene is derived, of 9 and $13 \%$ according to GOME2 and OMI, respectively, compared to the a priori estimate of $363 \mathrm{Tg}$ in 2010. The reduction is largest (up to 25-40\%) in the Southeastern US, in accordance with earlier studies. The GOME-2 and OMI satellite columns suggest a global pyrogenic flux decrease by 36 and $33 \%$, respectively, compared to the GFEDv3 (Global Fire Emissions Database) inventory. This decrease is especially pronounced over tropical forests, such as in Amazonia, Thailand and Myanmar, and is supported by comparisons with CO observations from IASI (Infrared Atmospheric Sounding Interferometer). In contrast 
to these flux reductions, the emissions due to harvest waste burning are strongly enhanced over the northeastern China plain in June (by ca. $70 \%$ in June according to OMI) as well as over Indochina in March. Sensitivity inversions showed robustness of the inferred estimates, which were found to lie within $7 \%$ of the standard inversion results at the global scale.

\section{Introduction}

Besides a small direct source, the dominant source of formaldehyde (HCHO) is its photochemical formation due to the oxidation of methane and non-methane volatile organic compounds (NMVOCs) emitted by the biosphere, vegetation fires and human activities. Methane oxidation is by far the largest contributor to the $\mathrm{HCHO}$ formation (ca. $60 \%$ on the global scale), while the remainder is due to oxidation of a large variety of VOCs of anthropogenic, pyrogenic and biogenic origin (Stavrakou et al., 2009a). The main removal processes (Sander et al., 2011) are the oxidation by $\mathrm{OH}$,

$\mathrm{HCHO}+\mathrm{OH}\left(+\mathrm{O}_{2}\right) \rightarrow \mathrm{CO}+\mathrm{HO}_{2}+\mathrm{H}_{2} \mathrm{O}$,

ultimately producing $\mathrm{CO}$ and converting $\mathrm{OH}$ to $\mathrm{HO}_{2}$ and photolysis reactions,

$$
\begin{aligned}
& \mathrm{HCHO}+h v \rightarrow \mathrm{CO}+\mathrm{H}_{2} \text { and } \\
& \mathrm{HCHO}+h v\left(+2 \mathrm{O}_{2}\right) \rightarrow \mathrm{CO}+2 \mathrm{HO}_{2},
\end{aligned}
$$

producing $\mathrm{CO}, \mathrm{H}_{2}$ and $\mathrm{HO}_{2}$ radicals.

Because of its short photochemical lifetime (ca. 4-5 h), and of the short lifetime of its main NMVOC precursors, most importantly isoprene, enhanced levels of $\mathrm{HCHO}$ are directly associated with the presence of nearby hydrocarbon emission sources. HCHO column densities retrieved from space by solar backscatter radiation in the UV-visible spectral region (Chance et al., 2000; De Smedt et al., 2008, 2012; Hewson et al., 2013; De Smedt et al., 2015; González Abad et al., 2015) are used to inform about the VOC precursor fluxes in a large body of literature studies. The first studies focused on the derivation of isoprene fluxes in the US constrained by HCHO columns from GOME (Global Ozone Monitoring Instrument) or OMI (Ozone Monitoring Instrument) instruments (Palmer et al., 2003, 2006; Millet et al., 2006, 2008). The estimation of isoprene emissions was extended to cover other regions, e.g., South America (Barkley et al., 2008, 2009) and Africa (Marais et al., 2012, 2014), with special efforts to exclude satellite scenes affected by biomass burning, and Europe (Dufour et al., 2009). Fu et al. (2007) reported top-down isoprene and anthropogenic reactive VOC fluxes over eastern and southern Asia and, more recently, anthropogenic emissions of reactive VOCs in eastern Texas were estimated using the oversampling technique applied to OMI HCHO observations (Zhu et al., 2014). Based on SCIAMACHY (Scanning Imaging Absorption Spectrometer for Atmospheric CHartographY) observations, spacebased emissions of isoprene and pyrogenic NMVOCs were derived on the global scale using the adjoint model approach (Stavrakou et al., 2009b, c). Each of those studies was constrained by one satellite data set and, in many cases, conflicting answers were found regarding the magnitude and/or spatiotemporal variability of the underlying VOC sources, mostly owing to differences in the satellite column products, in the models used to infer top-down estimates and in the emission inventories used as input in the models. The latter point is very often a source of confusion, since a very large range of estimates can be obtained using the same emission model depending on the choice of input variables. Indeed, the isoprene fluxes estimated using MEGAN (Model of Emissions of Gases and Aerosols from Nature) (Guenther et al., 2006), the most commonly used bottom-up emissions model for biospheric emissions, vary strongly depending on the driving variables used (e.g., meteorology, and land cover), leading to an uncertainty of about a factor of 5 for the global isoprene emissions (Arneth et al., 2011) and underscoring the need for clearly indicated a priori emission information in order to allow for meaningful comparisons between different studies.

Despite significant progress in the field, the derivation of VOC emissions using HCHO columns remains challenging, mainly owing to the large number and diversity of $\mathrm{HCHO}$ precursors, to uncertainties regarding their sources and speciation profiles, and to inadequate or incomplete knowledge of their chemical mechanisms and pathways leading to $\mathrm{HCHO}$ formation. In addition, it crucially depends on the quality of the satellite retrievals; therefore, efforts to address aspects such as instrumental degradation, temporal stability of the retrievals, noise reduction, and error characterization are of primary importance (De Smedt et al., 2012, 2015; Hewson et al., 2013; González Abad et al., 2015).

The advent of new satellites measuring at different overpass times, like GOME-2, SCIAMACHY and OMI, opens new avenues in the derivation of top-down estimates. However, it also raises new questions regarding the consistency of the estimated fluxes from different instruments. Indeed, a recent study focusing on tropical South America reported a factor of 2 difference between the SCIAMACHY- and OMIbased isoprene fluxes derived using the same model, a difference which apparently could not be explained by differences in the sampling features of the sensors or by uncertainties in the air mass factor calculations, and which might be partly due to model deficiencies pertaining to the diurnal cycle of the HCHO columns (Barkley et al., 2013).

The main objective of this study is therefore to address the issue of consistency between global VOC flux strengths inferred from one complete year of GOME-2 and OMI HCHO column densities, taking into account their different overpass times. Field campaign measurements show that the diurnal patterns of surface $\mathrm{HCHO}$ concentrations are mostly influ- 
enced by the magnitude and diurnal variability of precursor emissions and the development of the boundary layer. A midday peak followed by gradual decrease in the evening concentrations was observed at a tropical forest in Borneo (MacDonald et al., 2012), whereas HCHO concentration peaked in the evening during cool days and around midday in warm and sunny conditions at a forest site in California (Choi et al., 2010) and near a city location in the Po Valley (Junkermann, 2009). Long-term diurnal measurements of HCHO columns are limited but are less influenced by variations in boundary layer mixing and are directly comparable with the satellite observations. Here, we investigate first the diurnal variability of HCHO columns simulated by the IMAGESv2 global CTM (chemical transport model), and evaluate the model skill to reproduce the observed diurnal cycle of $\mathrm{HCHO}$ columns at seven different locations in Europe, China, and tropical regions.

Retrieved HCHO columns from GOME-2 and OMI, with local overpass times 09:30 and 13:30LT, respectively, are used to constrain the VOC emissions. The algorithms developed for the two sensors were designed to ensure the maximum consistency between the two sets of observations, as described in detail in De Smedt et al. (2015). The top-down emission estimates are derived using an inversion framework based on the adjoint of the IMAGESv2 CTM (Müller and Stavrakou, 2005; Stavrakou et al., 2009a) and fluxes are optimized per month, model grid and emission category (anthropogenic, biogenic and pyrogenic). The same inversion setup is applied using either GOME-2 or OMI measurements as top-down constraints for 2010, a particularly warm and dry year with intense fires and enhanced biogenic emissions. Sensitivity studies are carried out to assess the robustness of the findings to different assumptions, e.g., to changes of the prescribed a priori errors on the emission fluxes in the inversion.

In Sect. 2 the IMAGESv2 model is briefly described and the HCHO budget is discussed, whereas the formation of $\mathrm{HCHO}$ in the oxidation of anthropogenic VOCs is presented in detail in the Supplement. The modeled and observed diurnal cycle of HCHO columns is discussed in Sect. 3. The satellite $\mathrm{HCHO}$ columns used to constrain the inversions and the inversion methodology are presented in Sects. 4 and 5. An overview of the results inferred from the inversions using GOME-2 and OMI data and global results from sensitivity case studies are presented in Sect. 6. The VOC emissions inferred at the mid-latitudes (North America, China) and in tropical regions (Amazonia, Indonesia, Indochina, Africa) are thoroughly described in Sects. 7 and 8. Finally, conclusions are drawn in Sect. 9.

\section{HCHO simulated with IMAGESv2}

The IMAGESv2 global CTM is run at $2^{\circ} \times 2.5^{\circ}$ horizontal resolution and extends vertically from Earth's surface to the lower stratosphere through 40 unevenly spaced sigmapressure levels. It calculates daily averaged concentrations of 131 transported and 41 short-lived trace gases with a time step of $6 \mathrm{~h}$. Meteorological fields are obtained from ERA-Interim analyses of the European Centre of MediumRange Weather Forecasts (ECMWF). Advection is driven by monthly averaged winds, while the effect of wind temporal variability at timescales shorter than 1 month is represented as horizontal diffusion (Müller and Brasseur, 1995). Convection is parameterized based on daily ERA-Interim updraft mass fluxes. Turbulent mixing in the planetary boundary layer uses daily diffusivities also obtained from ERAInterim. Rain and cloud fields (and therefore also the photolysis and wet scavenging rates) are also based on daily ERA-Interim fields. The effect of diurnal variations are considered through correction factors on the photolysis and kinetic rates obtained from model simulations accounting for the diurnal cycle of photo rates, emissions, convection and boundary layer mixing (Stavrakou et al., 2009a). A thorough model description is given in Stavrakou et al. (2013) and references therein. The target year of this study is 2010 .

Anthropogenic emissions are obtained from the RETRO 2000 database (http://eccad.sedoo.fr; Schultz et al., 2008), except over Asia where the REASv2 (Regional Emission inventory in ASia) inventory for year 2008 is used (Kurokawa et al., 2013). The diurnal profile of anthropogenic emissions follows Jenkin et al. (2000). Isoprene emissions (including their diurnal, day-to-day and seasonal variations) are obtained from the MEGAN-MOHYCAN-v2 inventory (http://tropo.aeronomie.be/models/isoprene.htm; Müller et al., 2008; Stavrakou et al., 2014) and are estimated at $363 \mathrm{Tg}$ in 2010 (Fig. 1). Monthly averaged biogenic methanol emissions $\left(\sim 100 \mathrm{Tg} \mathrm{yr}^{-1}\right.$ globally $)$ are taken from a previous inverse modeling study (Stavrakou et al., 2011) using IMAGESv2 and methanol total columns from IASI (Infrared Atmospheric Sounding Interferometer). Biogenic emissions of acetaldehyde $\left(22 \mathrm{Tg} \mathrm{yr}^{-1}\right)$ and ethanol $\left(22 \mathrm{Tg} \mathrm{yr}^{-1}\right)$ are calculated following Millet et al. (2010). The model also includes the biogenic emissions of ethene, propene, formaldehyde, acetone and monoterpenes from MEGANv2 (http://eccad.sedoo.fr). Note that the non-isoprene biogenic VOC emissions are not varied in the source inversions.

Open vegetation fire emissions are taken from GFEDv3 (Global Fire Emissions Database; van der Werf et al., 2010), with emission factors for tropical, extratropical, savanna and peat fire burning provided from the 2011 update of the recommendations by Andreae and Merlet (2001). The GFEDv3 emission is estimated at $105.4 \mathrm{TgVOC}$ in 2010 , equivalent to $2.26 \mathrm{Tmol}$ (average molecular weight of $46.5 \mathrm{~kg} \mathrm{kmol}^{-1}$ ) (Fig. 1). The diurnal profile of biomass burning emissions was derived based on a complete year of geostationary active fires and fire radiative power observations from the SEVIRI (Spinning Enhanced Visible and InfraRed Imager) imager over Africa (Roberts et al., 2009). The analysis of the fire 


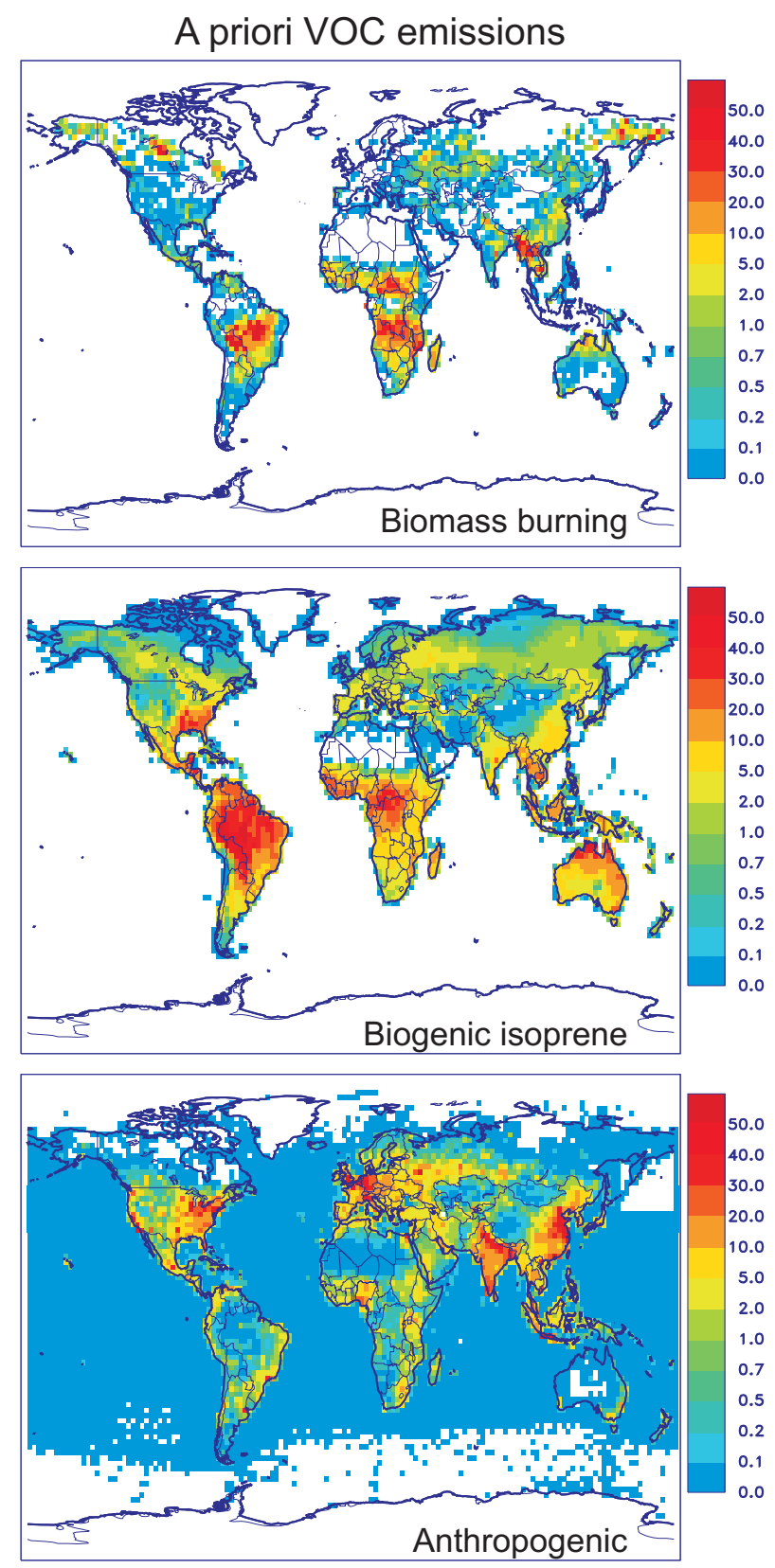

Figure 1. A priori annually averaged pyrogenic NMVOC, biogenic isoprene and anthropogenic NMVOC emissions used in the CTM. Units are $10^{10}$ molec $\mathrm{cm}^{-2} \mathrm{~s}^{-1}$.

cycle, performed over 20 different land cover types in northern and southern hemispheric Africa, exhibits strong diurnal variability and very similar patterns in both hemispheres. According to this data set, fire activity is negligible during the night and low in the early morning, it peaks around 13:30 LT and decreases rapidly in the afternoon hours. This profile is in fairly good agreement with the averaged diurnal cycle of active fire observations constructed from the GOES geostationary satellite encompassing North, Central and South America (Mu et al., 2011) and therefore it is applied to all fires worldwide. Note, however, that this specific temporal profile might not be appropriate for some locations, e.g., peat fires over Russia.

The vertical profiles of pyrogenic emissions are taken from a new global data set (Sofiev et al., 2013) of vertical smoke profiles from open fires, based on plume top heights computed by a semi-empirical model (Sofiev et al., 2012) and fire radiative power from the MODIS instrument. These profiles are highly variable depending on the season and the year. Forest regions are characterized by highaltitude plumes (up to 6-8 km), whereas grasslands generally emit within $2-3 \mathrm{~km}$. About half of the emitted flux is injected within the boundary layer. The 5th, median, 80th and 99th monthly percentiles of injection profile maps of this data set were obtained from the GlobEmission website (http://www.globemission.eu) and implemented in the CTM.

The chemical mechanism of isoprene oxidation accounts for $\mathrm{OH}$ recycling according to the Leuven isoprene mechanism LIM0 (Peeters et al., 2009; Peeters and Müller, 2010; Stavrakou et al., 2010) and its upgraded version LIM1 (Peeters et al., 2014). LIM1 is based on a theoretical reevaluation of the kinetics of isoprene peroxy radicals undergoing 1,5 and 1,6-shift isomerization and is in satisfactory agreement (factor of $\sim 2$ ) with experimental yields of the hydroperoxy aldehydes (HPALDs) believed to be major isomerization products (Crounse et al., 2011). Based on box model calculations using the kinetic preprocessor (KPP) chemical solver (Damian et al., 2002), the isomerization of isoprene peroxy radicals is estimated to decrease the molar $\mathrm{HCHO}$ yield by $\sim 8 \%$ in high $\mathrm{NO}_{x}$ conditions ( 2.39 vs.

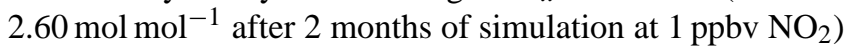
and by $\sim 15 \%$ in low $\mathrm{NO}_{x}$ conditions (1.91 vs. 2.25 after 2 months at $0.1 \mathrm{ppbv} \mathrm{NO}_{2}$ ). These estimated changes are however very uncertain, given their dependence on the unimolecular reaction rates of isoprene peroxy radicals and on the poorly constrained fate of the isomerization products.

The speciation profile for anthropogenic NMVOC emissions is based on the UK National Atmospheric Emissions Inventory (NAEI; Goodwin et al., 2001). According to NAEI, 49 (out of the 650 considered) compounds account for ca. $81 \%$ of the total UK emissions, 17 of them are explicitly accounted for in IMAGESv2 while a lumped compound of OAHC (other anthropogenic hydrocarbons) accounts for the remaining 32 species. The chemical mechanism of OAHC is adapted in order to reproduce the yields of $\mathrm{HCHO}$ from the mix of 32 higher NMVOCs. This is realized based on timedependent box model calculations using the semi-explicit Master Chemical Mechanism (MCMv3.2; http://mcm.leeds. ac.uk/MCM/, Saunders et al., 2003; Bloss et al., 2005). Details are given in the Supplement.

Based on IMAGESv2 model simulations, the global annual $\mathrm{HCHO}$ budget is estimated at $1600 \mathrm{Tg} \mathrm{HCHO}$ and is dominated by photochemical production, whereas less than $1 \%$ is due to direct emissions. The most important source of $\mathrm{HCHO}$ is methane oxidation ( $60 \%$ globally), the remainder 

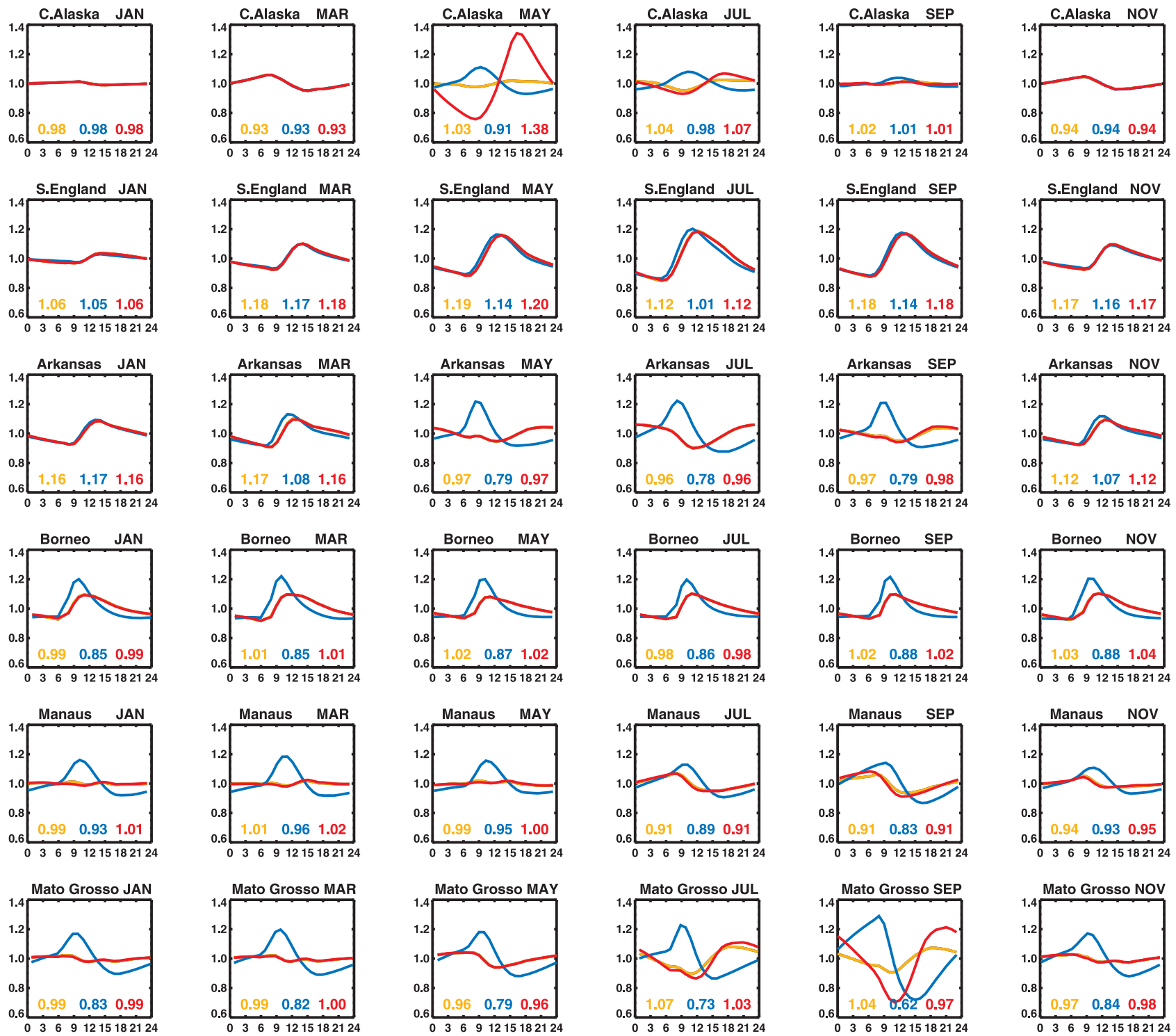

Figure 2. Modeled diurnal variations of $\mathrm{HCHO}$ columns (normalized at noon) at six locations, Central Alaska $\left(65^{\circ} \mathrm{N}, 151^{\circ} \mathrm{W}\right)$, South England $\left(51^{\circ} \mathrm{N}, 2.5^{\circ} \mathrm{W}\right)$, Arkansas $\left(35^{\circ} \mathrm{N}, 91^{\circ} \mathrm{W}\right)$, Borneo $\left(4^{\circ} \mathrm{N}, 117^{\circ} \mathrm{E}\right)$, Manaus $\left(3^{\circ} \mathrm{S}, 61^{\circ} \mathrm{W}\right)$, and Mato Grosso $\left(9^{\circ} \mathrm{S}, 51^{\circ} \mathrm{W}\right)$ in January, March, May, July, September and November 2010. The simulations STD, NBB, and NDC of Table 1 are shown in red, orange and blue, respectively. The modeled ratios of 13:30 to 09:30 LT columns are given inside each panel.

being due to the oxidation of biogenic (30\%), anthropogenic (7\%) and pyrogenic (3\%) hydrocarbons (Stavrakou et al., 2009a). The main removal process is photolysis, which accounts for $70 \%$ of the global sink, followed by $\mathrm{OH}$ oxidation (26\%) and by dry and wet deposition. The aforementioned production and loss processes result in a global lifetime of $4.6 \mathrm{~h}$.

\section{Diurnal cycle of HCHO columns}

\subsection{Model processes and sensitivity}

The top-down determination of VOC emissions based on GOME-2 and OMI data assumes that the model reproduces reasonably well the diurnal cycle of HCHO columns. To test this assumption would require a large number of welldistributed ground-based observations, which are however scarce and intermittent. We present further below a comparison with a limited data set of column observations at surface sites, most of which are located at or near pollution centers at mid-latitudes. In order to better characterize the diurnal 


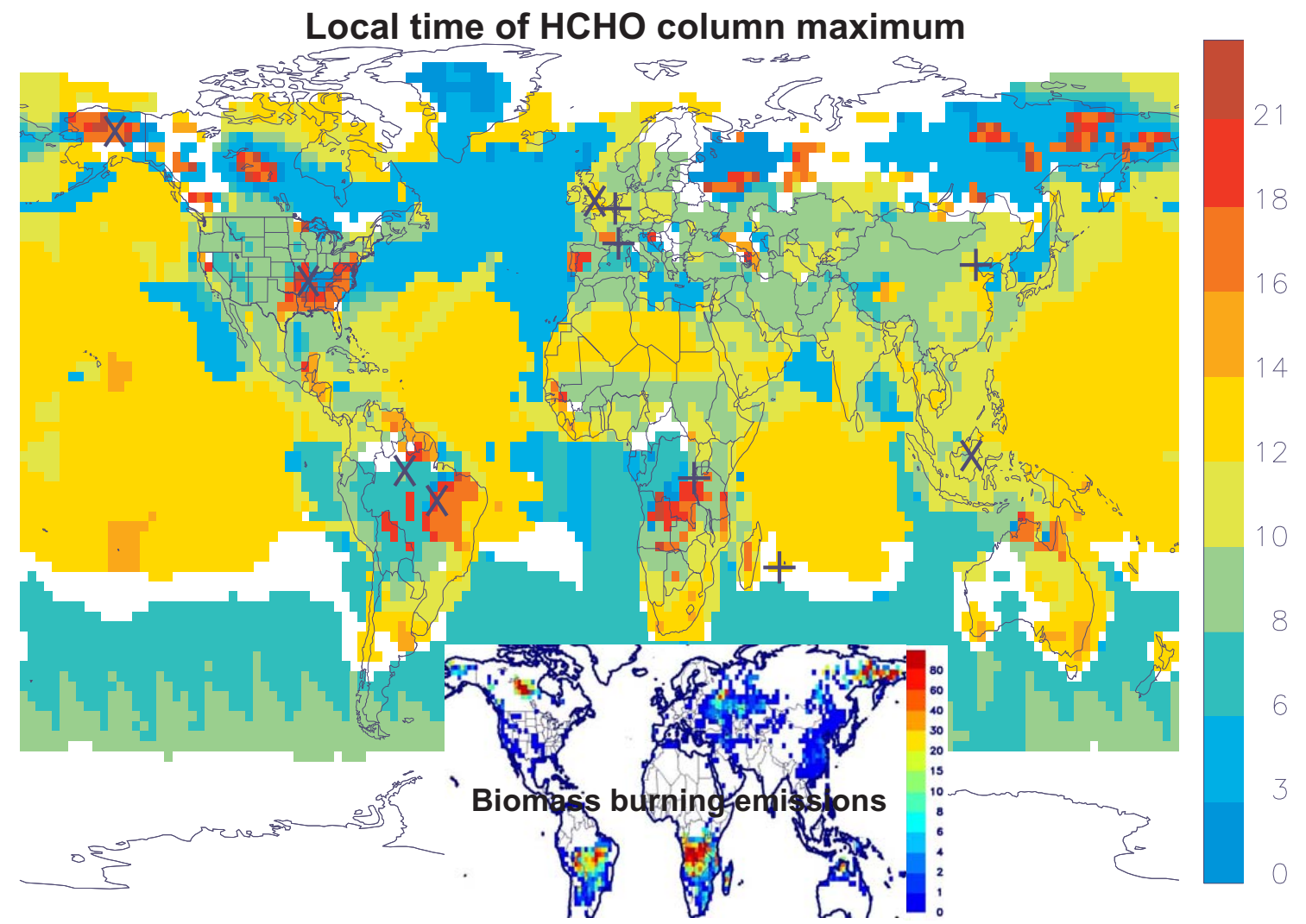

Figure 3. Modeled local time (in hours) of the maximum in HCHO column, for July 2010. The locations of sites for which comparisons are shown in Figs. 2, and 4 and 5 are shown as crosses (x) and plus symbols (+), respectively. White color represents regions with diurnal variability of less than $5 \%$. The distribution of open fire NMVOC emissions $\left(10^{10}\right.$ molec cm $\left.{ }^{-2} \mathrm{~s}^{-1}\right)$ for the same month is also shown inset.

Table 1. Model simulations conducted to investigate the diurnal cycle of HCHO columns (Sect. 3).

\begin{tabular}{ll}
\hline Name & Description \\
\hline STD & standard forward simulation \\
NBB & neglected biomass burning emissions \\
NDC & neglected the diurnal cycle of emissions \\
NDCBL & neglected diurnal cycle of boundary layer mixing \\
NDCC & neglected diurnal cycle of deep convection \\
\hline
\end{tabular}

cycle and to identify the factors influencing it in the model, we present in Fig. 2 the modeled diurnal variations of $\mathrm{HCHO}$ columns at selected locations and, in Fig. 3, the distribution of the local time of the maximum in the diurnal cycle of HCHO columns. Figure 2 also displays the results of sensitivity calculations described in Table 1, which neglect either the diurnal cycle of emissions (NDC) or the biomass burning emissions (NBB), in comparison to the standard model results. The results of additional sensitivity simulations related to vertical transport (Table 1) are very similar to the results of the base model simulation and not shown here for the sake of simplicity.
A striking feature of Figs. 2 and 3 is the large diversity of diurnal profiles across the seasons and locations. Very little $\mathrm{HCHO}$ variations are seen at high latitudes during the winter, due to the very low photochemical activity and absence of notable emissions. In regions where anthropogenic emissions are the dominant source of $\mathrm{HCHO}$ precursors, such as in northwestern Europe, eastern China, India and the Middle East (Fig. 1), the diurnal cycle displays a midday maximum and a minimum at the end of the night (Fig. 2, S. England; Fig. 3). As can be seen in Fig. 2, the diurnal cycle of anthropogenic emissions has a very small impact at these locations. This is due to the fairly long photochemical lifetimes of most anthropogenic NMVOCs. Their relatively low shortterm $\mathrm{HCHO}$ yields in comparison with the final yields (see Table S1 in the Supplement) implies that most HCHO formation occurs days after the precursor has been emitted. The midday maximum therefore reflects the diurnal cycle of $\mathrm{OH}$ concentrations, very low at night and at maximum when radiation is highest (Logan et al., 1981).

Over the eastern US, the wintertime (November-March) diurnal cycle displays a similar pattern due to anthropogenic emissions. In the summer, however, when biogenic isoprene is the dominant VOC, a completely different behavior is pre- 

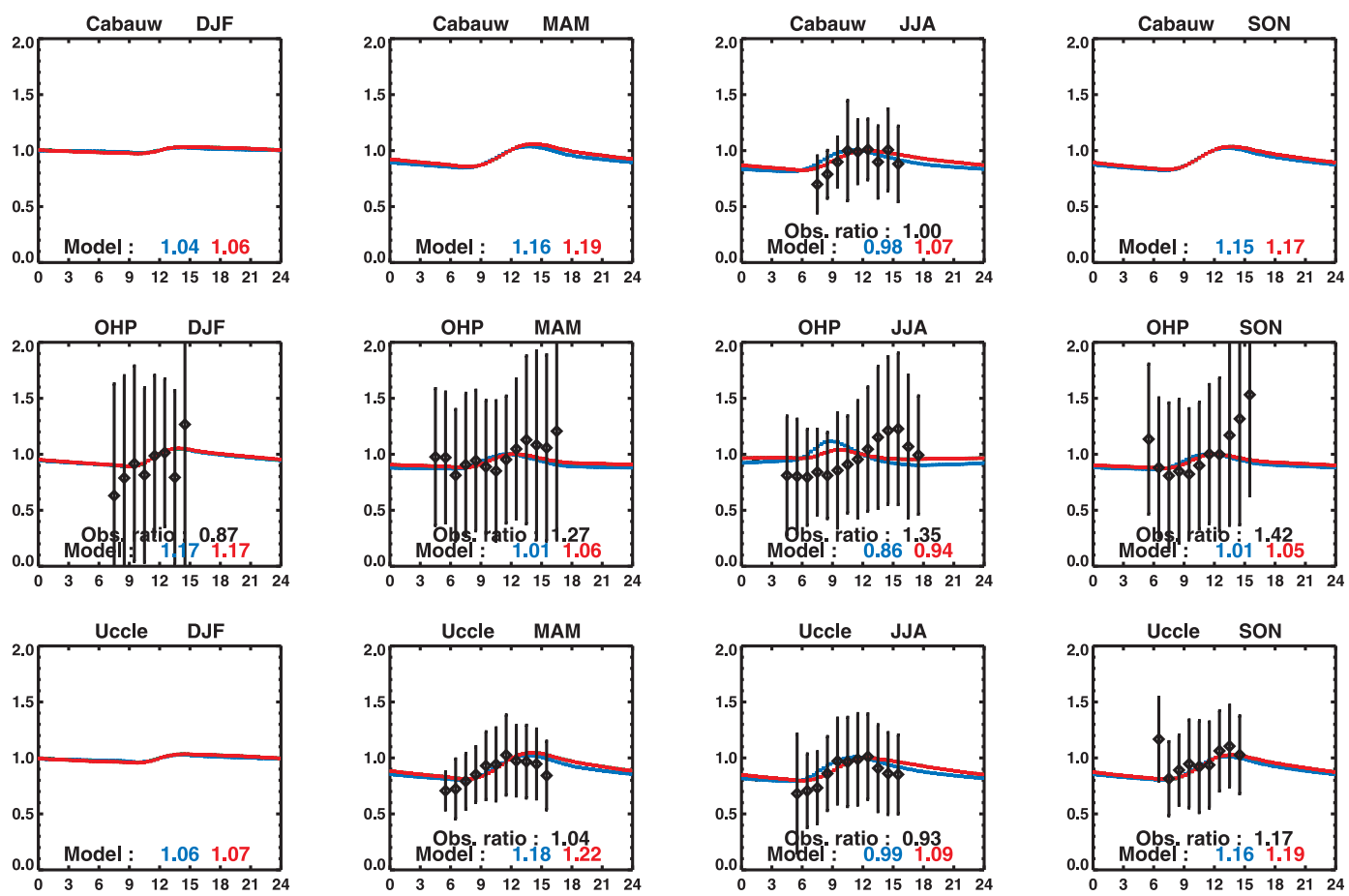

Figure 4. Seasonally averaged observed (black) and modeled (red) diurnal variations of HCHO columns normalized at noon at three European sites, Cabauw, Observatoire de Haute Provence, and Uccle. The observed columns are obtained using the MAX-DOAS technique (Sect. 3). The error bars correspond to the measurement standard deviation. Modeled columns calculated assuming no diurnal emission variability are shown in blue. The observed and modeled ratios (blue and red) of 13:30 to 09:30 LT columns are given inset.

dicted, with a noon minimum and a maximum in the evening or even in the early morning (Fig. 2, Arkansas; Fig. 3). A relatively similar pattern is found in the Manaus region in the Amazon in July-September (Fig. 2), in agreement with a previous modeling study using GEOS-Chem and focussing on Amazonia (Barkley et al., 2011). At all sites impacted by isoprene (Arkansas, Borneo, Manaus and Mato Grosso), the simulation neglecting diurnal variations of emissions (Fig. 2, NDC, blue curve) leads to a continuous HCHO buildup during the night and to a pronounced morning maximum followed by a gradual decrease during daytime until a minimum in the late afternoon or early evening. The nighttime buildup in that simulation follows the slow isoprene oxidation (mostly by ozone) and the near-absence of $\mathrm{HCHO}$ sinks, whereas the gradual $\mathrm{HCHO}$ decrease during the day reflects the decline of the accumulated isoprene and intermediate oxidation products due to $\mathrm{OH}$ oxidation. Although the daytime chemical lifetime of isoprene is short (less than $1 \mathrm{~h}$ at an $\mathrm{OH}$ concentration of $4 \times 10^{6} \mathrm{molec} \mathrm{cm}^{-3}$ ), a large fraction of the formaldehyde production due to isoprene involves longer-lived intermediates (such as methyl vinyl ketone, methacrolein, hydroxyacetone, and hydroperoxides) resulting in a delayed formaldehyde production.

When the diurnal cycle of isoprene emissions is taken into account (Fig. 2, STD, red curve), the midday emission maximum leads to a $\mathrm{HCHO}$ minimum and to an increase afterwards, due to the delayed production from isoprene (Arkansas, Manaus and Mato Grosso). It has been pointed out (Barkley et al., 2011) that the nighttime HCHO accumulation and morning maximum near Manaus in September might be unrealistic, as models are often unable to reproduce the observed rapid decline of isoprene concentrations during the evening at different surface sites. Nighttime chemistry, deposition and boundary layer processes might indeed be poorly represented in models, causing significant deviations from the patterns described above. As is obvious from Figs. 2 and 3 , different locations or seasons often display very different diurnal patterns, for complex reasons including radiation and $\mathrm{NO}_{x}$ levels, the occurrence of biomass burning, mixing processes, etc. Note, however, that sensitivity simulations neglecting the diurnal cycle of boundary layer mixing and deep convection fluxes were found to cause only minimal deviations from the columns of the standard model calculations.

Vegetation fires are found to cause locally very strong variations with maximum values in the evening, exceeding by up to $70 \%$ the morning minimum value (Central Alaska in May and July, Mato Grosso in September). As seen in Fig. 3, strong emissions over eastern Siberia, European Russia, central Canada, Angola, Brazil and northern Australia are most often associated with HCHO column maxima in the late afternoon and evening. 

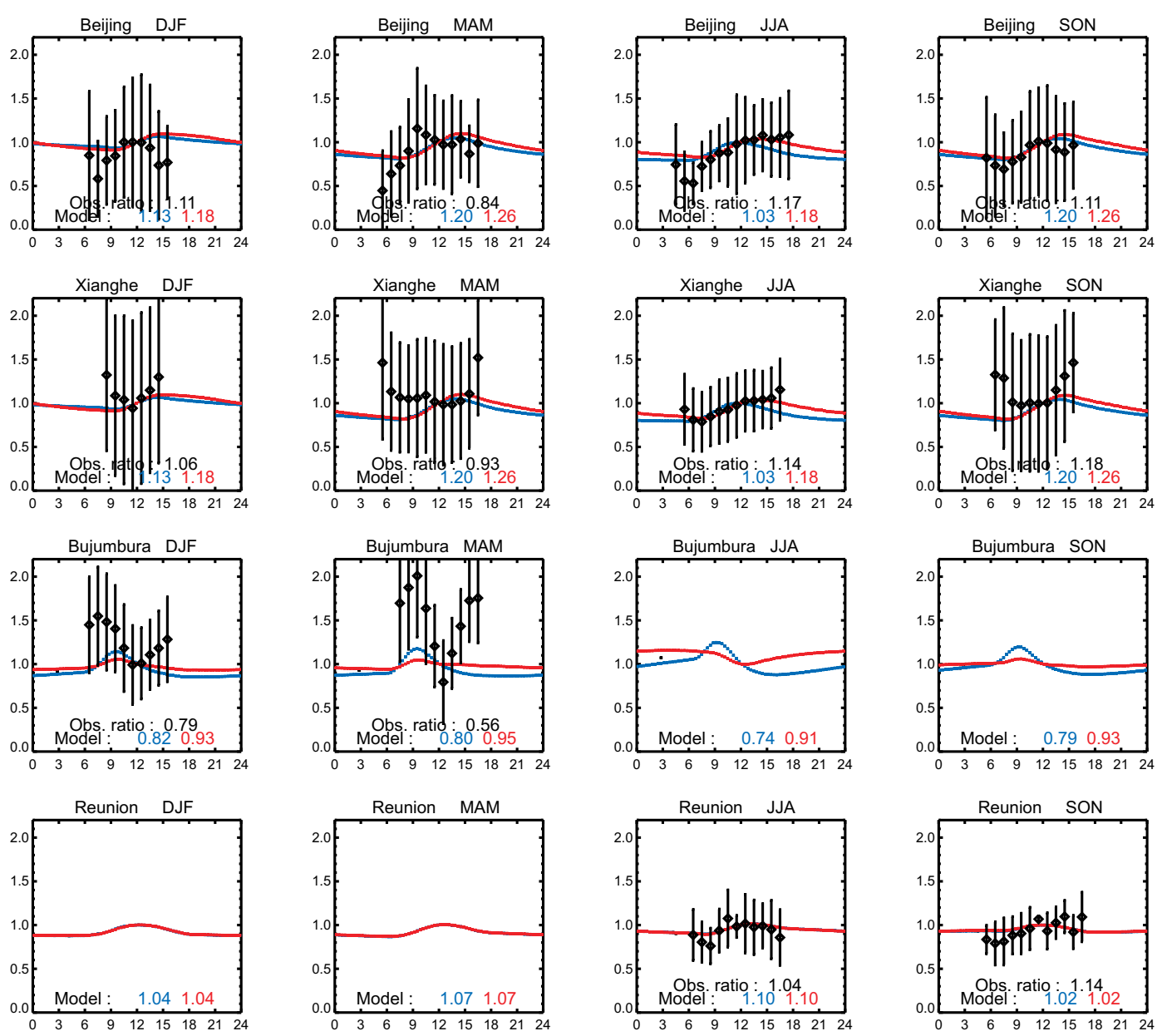

Figure 5. As in Fig. 4, comparison between modeled and observed diurnal variations for four sites : Beijing, Xianghe, Bujumbura and Reunion Island. The observations were obtained using the MAX-DOAS (Beijing, Xianghe, Bujumbura) and FTIR (Reunion Island) techniques.

\subsection{Model evaluation}

To evaluate the diurnal cycle of the modeled HCHO column, we use ground-based, remotely sensed measurements at the seven following sites:

1. Cabauw, the Netherlands $\left(52^{\circ} \mathrm{N}, 5^{\circ} \mathrm{E}\right), 8$ June-21 July 2009 (Pinardi et al., 2013).

2. Observatoire de Haute Provence (OHP), France $\left(43.94^{\circ} \mathrm{N}, 5.71^{\circ} \mathrm{E}\right), 26$ June 2007-20 March 2013 (Valks et al., 2011).

3. Uccle, Belgium $\left(50.78^{\circ} \mathrm{N}, 4.35^{\circ} \mathrm{E}\right), 1$ May $2011-$ 23 April 2012 (Gielen et al., 2014).

4. Beijing, China $\left(39.98^{\circ} \mathrm{N}, 116.38^{\circ} \mathrm{E}\right), 3$ July 2008 17 April 2009 (Vlemmix et al., 2015, see also Hendrick et al., 2014).

5. Xianghe, China $\left(39.75^{\circ} \mathrm{N}, 116.96^{\circ} \mathrm{E}\right), 7$ March 2010 26 December 2013 (Vlemmix et al., 2015, see also Hendrick et al., 2014).
6. Bujumbura, Burundi ( $\left.3^{\circ} \mathrm{S}, 29^{\circ} \mathrm{E}\right), 25$ November $2013-$ 22 January 2014 (De Smedt et al., 2015).

7. Reunion Island, France $\left(20.9^{\circ} \mathrm{S}, 55.5^{\circ} \mathrm{E}\right), 1$ August 2004-25 October 2004, 21 May 2007-15 October 2007. 2 June 2009-28 December 2009, and 11 January 2010 16 December 2010 (Vigouroux et al., 2009).

The MAX-DOAS (Multi-axis differential optical absorption spectroscopy) technique (Hönninger et al., 2004; Platt and Stutz, 2008) was used in all cases, except at Reunion Island where the FTIR (Fourier transform infrared spectroscopy) technique is used (Griffiths and de Haseth, 2007; Vigouroux et al., 2009). Total HCHO columns are measured at all stations, and profiles are also measured at Beijing, $\mathrm{Xi}$ anghe, and Bujumbura.

Figures 4 and 5 illustrate the diurnal cycle of observed and modeled HCHO columns seasonally averaged and normalized by their noon values. The ratio of the observed columns at 13:30 and 09:30 LT ranges mostly between 0.8 and 1.2 , although values close to 1.4 are found at one site (OHP). The 
modeled values of this ratio are most often higher than in the measurements, except at OHP. The average ratio at all sites and seasons is slightly higher in the model (1.126) than in the data (1.043), although the average absolute deviation between model and data is large $(20 \%)$, presumably mostly because of representativity issues. The coarse resolution of the model makes it impossible to reproduce the very large differences seen, for example, between the observed diurnal profiles at Beijing and Xianghe, two sites very near to each other and within the same model grid cell. OHP similarly lies in a region with strong gradients in the diurnal behavior of the columns, as seen in Fig. 3.

Nevertheless, the diurnal cycle of HCHO columns at the four most polluted sites (Uccle, Cabauw, Beijing and Xianghe) shows a consistent pattern during summertime (also in spring and fall at Uccle) which is well reproduced by the model. Additionally, at Reunion Island, the observed midday maximum is well reproduced by the model. As pointed out above, the midday maximum at both very remote and very polluted sites is primarily caused by the diurnal cycle of $\mathrm{OH}$ levels, as the reaction with $\mathrm{OH}$ of the (mostly fairly longlived) anthropogenic VOCs as well as methane is the main source of HCHO in those areas. In the Beijing area, the diurnal cycle of emissions is responsible for a slight delay in the maximum towards the afternoon, in agreement with the observations.

A broader network of measurements would be necessary to provide a more detailed assessment of HCHO column diurnal variations, in particular over forests and in biomass burning areas. Nevertheless, the comparison presented above with the limited data set of available measurements revealed no large systematic discrepancies, except for a slight overestimation (by $8 \%$ ) of the average ratio of 13:30 to 09:30 LT columns.

\section{Satellite observations}

The current version (v14) of the HCHO retrievals applied to GOME-2/Metop-A and OMI/Aura measurements is based on the algorithm developed for GOME-2 (version 12, De Smedt et al., 2012), with significant adaptations, as detailed below.

A classical DOAS algorithm is used, including three main steps: (1) the fit of absorption cross-section databases to the measured Earth reflectance in order to retrieve HCHO slant columns, (2) a background normalization procedure to eliminate remaining unphysical dependencies, and (3) the calculation of tropospheric air mass factors using radiative transfer calculations and modeled a priori profiles. In GOME-2 v12, two fitting intervals were introduced to improve the treatment of $\mathrm{BrO}$ absorption features, and to reduce the noise on the HCHO columns (328.5-359 nm for the pre-fit of $\mathrm{BrO}, 328.5-$ $346 \mathrm{~nm}$ for the fit of HCHO) (De Smedt et al., 2012).
In the current version, a third fitting interval (339-364 nm) is used to pre-fit the $\mathrm{O}_{2}-\mathrm{O}_{2}$ slant columns in order to minimize the effect of spectral interferences between the molecular absorptions. This results in a global reduction of the HCHO slant columns over the continents compared to the previous version, by $0-25 \%$, depending on the season and the altitude. It is interesting to note that the effect is very similar when applied to GOME-2 and OMI HCHO retrievals, i.e., it has little or no impact on the diurnal variations (De Smedt et al., 2015). In order to improve the fit of the slant columns, an iterative DOAS algorithm for removal of spike residuals has been implemented (Richter et al., 2011). In addition, this version of the algorithm makes use of radiance spectra, daily averaged in the equatorial Pacific, which serve as reference spectra. The background normalization now depends on the day, the latitude, and on the viewing zenith angle of the observation. This also serves as a destriping procedure, needed for an imager instrument such as OMI (Boersma et al., 2011). The air mass factor calculation is based on Palmer et al. (2001). Scattering weighting functions are calculated with the LIDORT v3.3(linearized discrete ordinate radiative transfer) radiative transfer model (Spurr, 2008).

The a priori profile shapes are provided by the IMAGES model, at 09:30 LT for GOME-2 and 13:30 LT for OMI (cf. Sect. 2). The OMI-based surface reflection database from Kleipool et al. (2008) is used for both GOME-2 and OMI. Radiative cloud effects are corrected using the independent pixel approximation (Martin et al., 2002) and the respective cloud products of the instruments provided by the TEMIS website (http://www.temis.nl), namely the GOME-2 $\mathrm{O}_{2}$ Aband Frescov6 product (Wang et al., 2008) and the $\mathrm{OMI} \mathrm{O}_{2}-$ $\mathrm{O}_{2}$ cloud product (Stammes et al., 2008). As for the previous algorithm versions, v14 HCHO columns are openly available on the TEMIS website (http://h2co.aeronomie.be/).

Monthly averaged HCHO columns from both instruments gridded onto the resolution of the model are used as topdown constraints. The simulated monthly averaged columns are calculated from daily values weighted by the number of satellite (OMI or GOME-2) measurements for each day at each model grid cell. Columns with a cloud fraction higher than $40 \%$ are excluded from the averages. HCHO data are also excluded over oceanic IMAGES grid cells (for which the land fraction is lower than 0.2 ), since we aim to constrain only continental sources, as well as in the region of the South Atlantic geomagnetic anomaly, i. e. within less than $1500 \mathrm{~km}$ of its assumed epicenter $\left(47.0^{\circ} \mathrm{W}, 24.9^{\circ} \mathrm{S}\right)$. Finally, regridded columns for which the monthly and spatially averaged retrieval error exceeds $100 \%$ are also rejected. The error of the satellite columns is defined as the square root of the squared sum of the retrieval error and an absolute error of $2 \times 10^{15}$ molec $\mathrm{cm}^{-2}$. In most VOC-emitting regions the error ranges between 40 and $60 \%$.

The monthly regridded $\mathrm{HCHO}$ columns from GOME-2 and OMI are shown in Fig. 6 for July 2010. As seen in this 

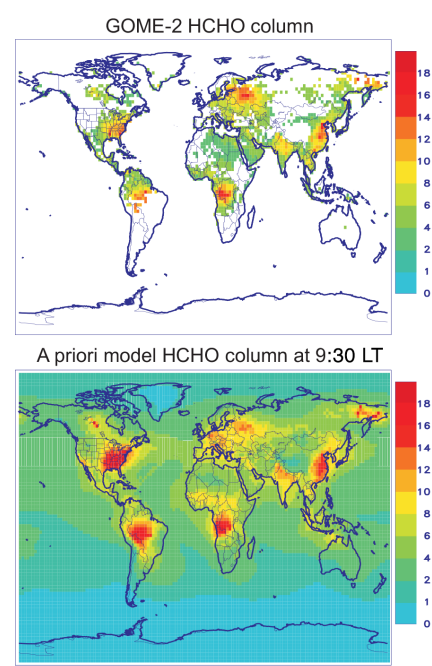

Optimized $\mathrm{HCHO}$ column at 9:30 LT
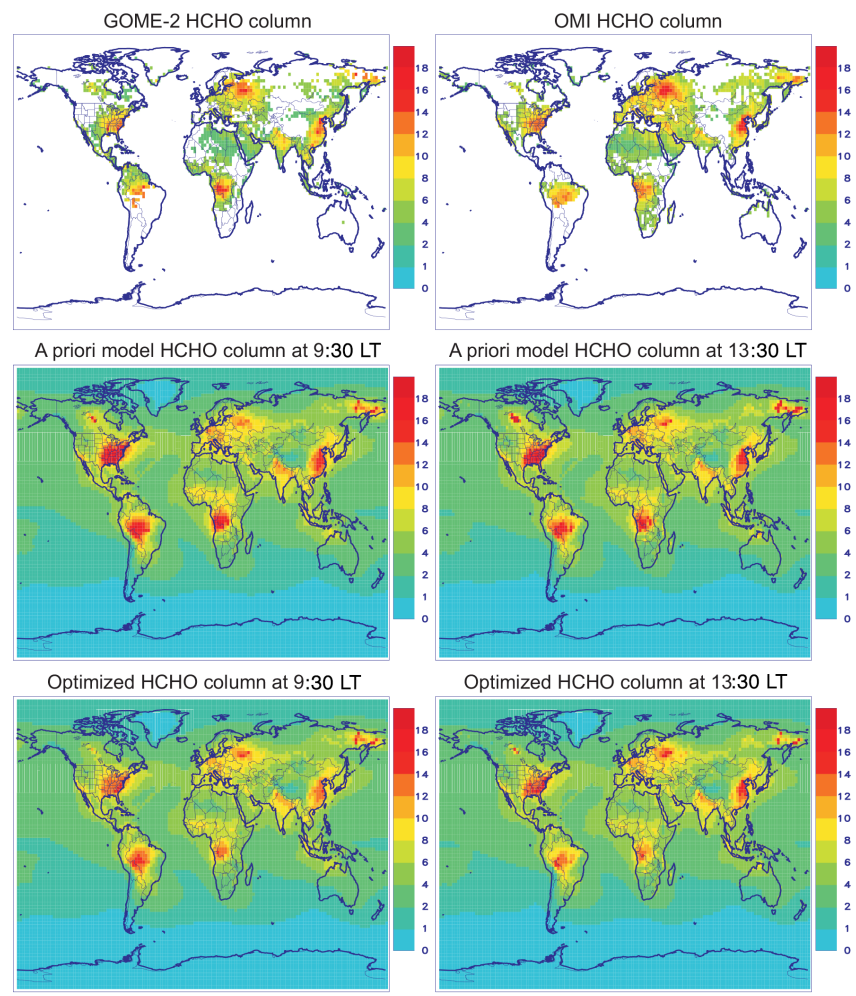

Optimized HCHO column at 13:30 LT

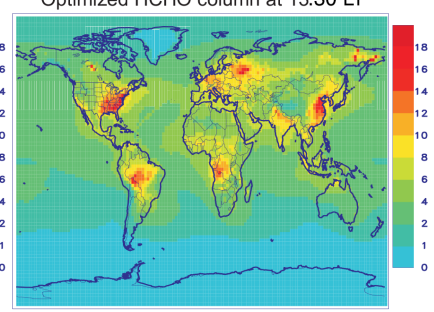

Figure 6. Observed (upper panels) HCHO columns by GOME-2 and OMI instruments in July 2010. Simulated HCHO columns using IMAGESv2 CTM at the overpass times of GOME-2 and OMI (middle panels), and optimized modeled columns derived from the inversions using GOME-2 data (left) and OMI columns (right). The columns are expressed in $10^{15}$ molec $\mathrm{cm}^{-2}$.

figure, and discussed in De Smedt et al. (2015), the early afternoon columns of OMI are higher than the mid-morning values of GOME-2 at mid-latitudes, while the reverse is true at most tropical locations, in qualitative agreement with the ground-based measurements and modeling results (Figs. 4, $5)$.

\section{Inversion methodology}

The flux inversion technique consists in minimizing the mismatch between the model predictions and a set of chemical observations by adjusting the a priori emission distributions $\Phi_{i}(x, t)$, where $(x, t)$ denote the spatial (latitude, longitude) and temporal (year, month) variables, and $i$ the different emission categories (biogenic, pyrogenic, and anthropogenic). We express the optimized solution $\Phi_{i}^{\text {opt }}(x, t)$ as

$\Phi_{i}^{\mathrm{opt}}(x, t)=\sum_{j=1}^{m} e^{f_{j}} \Phi_{i}(x, t)$,

where $\boldsymbol{f}=\left(f_{j}\right)$ is a vector of scaling factors (in log space) multiplying the a priori emissions. This vector is determined
Table 2. Performed flux inversions.

\begin{tabular}{|c|c|}
\hline Name & Description \\
\hline GOME-2 & use GOME-2 data \\
\hline OMI & use OMI data \\
\hline OMI-DE & doubled a priori errors on the emission fluxes \\
\hline OMI-HE & halved a priori errors on the emission fluxes \\
\hline OMI-CF & use only OMI data with cloud fraction $<0.2$ \\
\hline OMI-IS & ignore isomerization of isoprene peroxy radicals \\
\hline
\end{tabular}

so as to minimize the scalar function $J$ (also termed as cost function)

$J(\boldsymbol{f})=\frac{1}{2}\left((H(\boldsymbol{f})-y)^{\mathrm{T}} \mathbf{E}^{-1}(H(\boldsymbol{f})-y)+\boldsymbol{f}^{\mathrm{T}} \mathbf{B}^{-1} \boldsymbol{f}\right)$,

which measures the discrepancy between the modeled HCHO columns $H(\boldsymbol{f})$ and the observations $y$. In this expression ${ }^{\mathrm{T}}$ is the transpose of the matrix, $\mathbf{E}$ and $\mathbf{B}$ are the matrices of errors on the observations $y$ and on the variables $f$, respectively. The gradient of the cost function $J$ with respect to the input variables $(\partial J / \partial f)$ is calculated using the adjoint of the model. A thorough description of the method and its implementation in the IMAGESv2 CTM is given in Müller and Stavrakou (2005) and Stavrakou et al. (2009b). The inversion is performed at the model resolution $\left(2^{\circ} \times 2.5^{\circ}\right)$ using an iterative algorithm suitable for large-scale problems (Gilbert and Lemaréchal, 1989).

The source inversions presented in Table 2 infer the emission rates of the three emission categories (anthropogenic, biogenic and biomass burning) are adjusted per month and are constrained by either GOME-2 or OMI HCHO columns. On the global scale, ca. 63000 flux parameters are varied. The emission of a grid cell is not optimized when its maximum a priori monthly value is lower than $10^{10}$ molec $\mathrm{cm}^{-2} \mathrm{~s}^{-1}$. The assumed error on the a priori anthropogenic emission by country is set equal to a factor of 1.5 and 2 for OECD (Organisation for Economic Co-operation and Development) and other countries, respectively, to a factor of 2 for biogenic emissions and to a factor of 3 for fire burning emissions (Stavrakou et al., 2009b).

The sensitivity studies (Table 2) aim at assessing the impact of (i) the choice of a priori errors on the emission fluxes (OMI-DE, OMI-HE), (ii) the cloud fraction filter applied to the satellite data (OMI-CF), and (iii) the isomerization of isoprene peroxy radicals (OMI-IS). The annual a priori and topdown fluxes of the two standard and the four sensitivity inversions are summarized in Table 3 . The a priori model columns calculated at 09:30 and 13:30 LT are generally higher than the GOME-2 or OMI HCHO column abundances (Fig. 6), e.g., over Europe, southern China, the United States, Amazonia and Northern Africa. They are, however, found to agree generally well in terms of seasonality (Fig. 7). 
Table 3. A priori and top-down VOC emissions $\left(\mathrm{Tg} \mathrm{yr}^{-1}\right)$ by region. The emission inversions are defined in Table 2. The regions are defined as follows. North America: US and Canada, Southern America: Mexico, Central and South America, Northern (Southern) Africa: north (south) of the Equator, Tropics: $25^{\circ} \mathrm{S}-25^{\circ} \mathrm{N}$, Southeastern US: $25-38^{\circ} \mathrm{N}, 60-100^{\circ} \mathrm{W}$, Amazonia: $14^{\circ} \mathrm{S}-10^{\circ} \mathrm{N}, 45-80^{\circ} \mathrm{W}$, Indonesia: $10^{\circ} \mathrm{S}-6^{\circ} \mathrm{N}, 95-142.5^{\circ} \mathrm{E}$, Indochina: 6-22 ${ }^{\circ} \mathrm{N}, 97.5-110^{\circ} \mathrm{E}$, Europe extends to the Urals $\left(55^{\circ} \mathrm{E}\right)$, FSU $=$ Former Soviet Union.

\begin{tabular}{lrrrrrrr}
\hline Biomass burning $\left(\mathrm{TgVOC} \mathrm{yr}^{-1}\right.$ ) & A priori & GOME-2 & OMI & OMI-DE & OMI-HE & OMI-CF & OMI-IS \\
\hline North America & 5.3 & 3.6 & 3.3 & 5.3 & 2.9 & 4.6 & 3.2 \\
Southern America & 36.9 & 20.7 & 17.1 & 16.8 & 17.8 & 16.4 & 16.2 \\
Amazonia & 26.5 & 13.0 & 10.4 & 10.2 & 10.8 & 10.0 & 9.7 \\
Northern Africa & 14.9 & 8.6 & 8.8 & 8.8 & 9.2 & 9.7 & 8.1 \\
Southern Africa & 25.8 & 17.6 & 23.8 & 24.6 & 23.0 & 25.5 & 23.1 \\
Indochina & 6.2 & 4.6 & 5.3 & 5.6 & 4.7 & 5.6 & 5.0 \\
Tropics & 93.3 & 56.8 & 60.6 & 61.6 & 60.4 & 63.0 & 57.8 \\
Extratropics & 12.0 & 10.0 & 9.9 & 13.4 & 8.8 & 12.1 & 9.2 \\
Global & 105.4 & 67.0 & 70.5 & 74.9 & 69.1 & 75.1 & 67.1 \\
\hline Isoprene (Tg yr ${ }^{-1}$ ) & $\mathrm{A}$ priori & GOME-2 & OMI & OMI-DE & OMI-HE & OMI-CF & OMI-IS \\
\hline Europe (excl. FSU) & 3.8 & 3.3 & 3.8 & 3.7 & 3.4 & 3.9 & 3.7 \\
Europe & 7.4 & 6.9 & 8.2 & 8.8 & 7.7 & 8.6 & 8.1 \\
North America & 34.7 & 26.5 & 29.9 & 28.0 & 31.9 & 30.4 & 28.6 \\
Southeastern US & 14.5 & 8.9 & 10.8 & 9.8 & 12.2 & 11.3 & 9.9 \\
Southern America & 149.5 & 142.1 & 121.2 & 115.9 & 128.9 & 125.6 & 114.0 \\
Amazonia & 99.4 & 92.5 & 73.7 & 69.1 & 80.6 & 77.2 & 67.9 \\
Northern Africa & 50.6 & 45.3 & 43.7 & 40.4 & 46.8 & 44.7 & 41.5 \\
Southern Africa & 31.0 & 31.3 & 31.5 & 32.8 & 31.0 & 34.2 & 30.7 \\
Indonesia & 11.6 & 10.3 & 11.1 & 10.5 & 11.4 & 10.6 & 10.9 \\
Indochina & 7.6 & 7.1 & 7.5 & 7.3 & 7.5 & 7.4 & 7.3 \\
Tropics & 314.8 & 291.1 & 272.3 & 261.9 & 286.2 & 281.3 & 260.2 \\
Extratropics & 48.3 & 39.4 & 44.7 & 44.1 & 45.8 & 46.4 & 43.3 \\
Global & 363.1 & 330.5 & 317.0 & 305.9 & 332.1 & 327.8 & 303.5 \\
\hline Anthropogenic (TgVOC yr ${ }^{-1}$ ) & A priori & GOME-2 & OMI & OMI-DE & OMI-HE & OMI-CF & OMI-IS \\
\hline Global & 155.6 & 138.6 & 157.5 & 162.0 & 154.2 & 163.4 & 155.8 \\
\hline & & & & & & &
\end{tabular}

\section{Overview of the results}

Globally, the cost function is reduced by a factor of 2 after optimization, and its gradient is reduced by a factor of ca. $10^{3}$. In general, the consistency between the two inversions is highest in tropical regions. At mid-latitudes, the emission updates (i.e., the ratios of optimized to prior emissions) are almost systematically higher in the OMI-based inversion than in the GOME-2-based inversion. This reflects ratios of 13:30 to 09:30 LT columns which are lower in the model than suggested by the two satellite data sets.

Both GOME-2 and OMI inversions suggest a strong decrease in global biomass burning VOC emissions with regard to the a priori GFEDv3 inventory, by 36 and $33 \%$, respectively. This decrease is most pronounced in tropical regions. In contrast, both the OMI and GOME-2 optimizations lead to enhanced emissions (by about $50 \%$ ) due to the extensive fires which plagued European Russia in August 2010 (Sect. 7.2) and to agricultural waste burning in the North China Plain in June (Sect. 7.3). The fire burning estimates from the two base inversions are generally quite con- sistent, not only globally but also over large emitting regions like Amazonia, southeastern Asia, and Africa. The sensitivity studies provide global flux estimates which are close (within $7 \%$ ) to the standard top-down results using OMI.

The globally derived isoprene fluxes are reduced in both standard inversions, by $9 \%$ according to GOME- 2 and by $13 \%$ according to OMI, compared to the a priori estimate of the MEGAN-ECMWF-v2 inventory $\left(363.1 \mathrm{Tg} \mathrm{yr}^{-1}\right.$, Table 3). The overall consistency between the global estimates is high for this emission category, despite some significant differences at a regional scale (cf. next sections). The biogenic top-down fluxes derived from the sensitivity inversions of Table 2 lie within $5 \%$ of the OMI-based estimates on the global scale, yet larger differences are found in the regional scale.

Finally, the global anthropogenic source is decreased in the GOME-2 inversion, while it is slightly increased in the inversion using OMI. Despite their limited capability to constrain this emission category on the global scale due to its small contribution to the global HCHO budget (Stavrakou et al., 2009a), the satellite observations are found to provide 

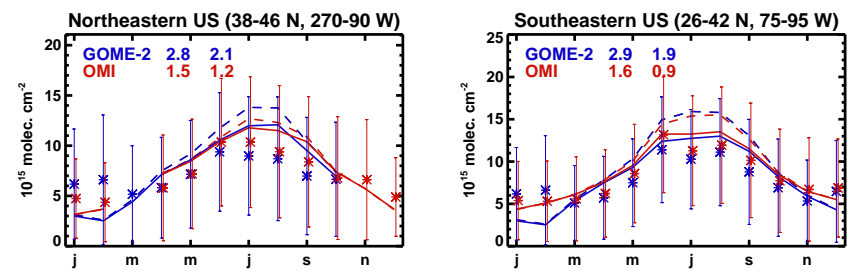

Southern China (18-34 N, 110-120 E)

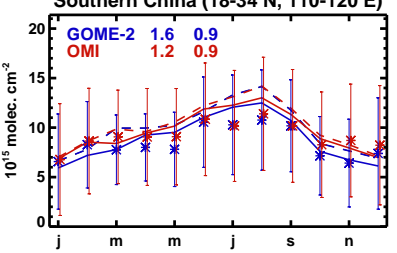

Congo (2-10 S, 15-30 E)
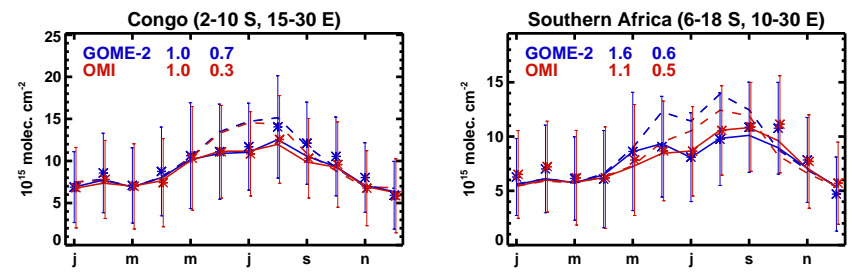

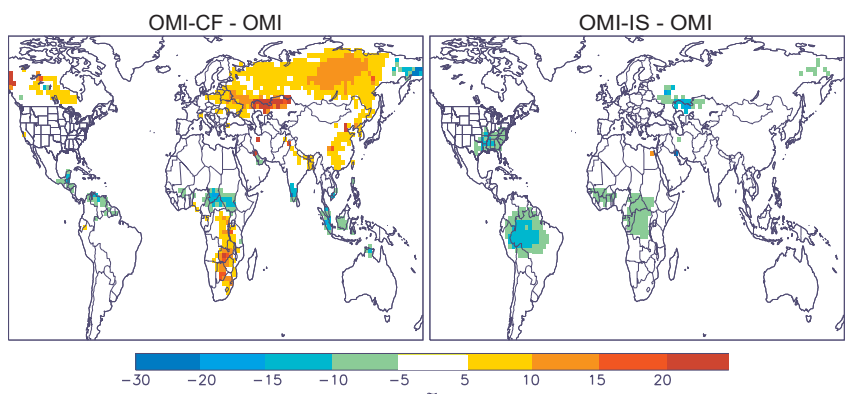

Figure 8. Percentage difference of the total VOC emissions inferred by the sensitivity inversions (OMI-CF, left panel, and OMI-IS, right panel) and the standard OMI inversion for the month of July (see Table 2).

Figure 7. Monthly averages of observed GOME-2 (blue asterisks) and OMI (red asterisks) HCHO columns and modeled columns over nine selected regions. Dashed and solid lines correspond to a priori and optimized model columns, respectively, calculated at 09:30 LT (in blue) and at 13:30 LT (in red). The units are $10^{15}$ molec $\mathrm{cm}^{-2}$. The mean absolute deviation between the a priori (left) and optimized (right) modeled columns and the observed columns is given inset in each panel (in blue for GOME-2, in red for OMI). Error bars (blue for GOME-2, red for OMI) represent the retrieval error provided for each data set.

constraints over highly polluted regions, notably in eastern China where the discrepancy between the two sensors is most evident (see Sect. 7.3).

Annual emission updates for the different source categories and the monthly variation of the a priori and optimized flux estimates are illustrated in Figs. 9-13.

Modifying the errors on the flux parameters infers global isoprene emission decreases of $8.5 \%$ (OMI-HE) and 16\% (OMI-DE) with regard to the initial isoprene inventory and within $7 \%$ of the standard OMI inversion; cf. Table 3. As expected, due to the limited or stronger confidence assigned to the a priori inventories in OMI-DE and OMI-HE scenarios, respectively, most substantial departures from the a priori inventory are obtained when doubling the errors on the emission parameters, while the OMI-HE scenario lies closer to the a priori database. The impact of the use of a stricter cloud criterion on the OMI scenes used as top-down constraints (20\% for OMI-CF instead of $40 \%$ in OMI base inversion) results in weak increases of the globally inferred fluxes with respect to the OMI inversion, but the enhancement is more important in extratropical regions and amounts to $22 \%$ for biomass burning emissions (Table 3 and left panel of Fig. 8). Finally,

suppressing the isomerization channel in isoprene oxidation increases the $\mathrm{HCHO}$ yield from isoprene and leads to slightly higher model columns over isoprene-rich regions. As seen in the right panel of Fig. 8, the resulting isoprene fluxes are only slightly lower compared to the reference run (by $4 \%$ lower on the global scale). Over Amazonia, this emission reduction reaches $8 \%$.

\section{Emissions at the mid-latitudes}

\subsection{North America}

Biogenic isoprene emissions drive the HCHO column seasonality and explain the summertime column peak in the eastern US (Fig. 7). The a priori model exhibits, however, a much stronger seasonal variability than the observation with a summer to winter ratio of 4-5 compared to the observed ratio of about 2 . In the summertime, the a priori model overestimates the GOME- 2 and OMI measurements by up to 50 and $35 \%$, respectively, in the eastern US. This drives the significant decrease in the optimized isoprene fluxes, from the a priori value of 17.8 to $11.6 \mathrm{Tg}$ (GOME-2) and to $13.8 \mathrm{Tg}$ (OMI) over the US in 2010, in good agreement with our earlier flux estimates $\left(13 \mathrm{Tg} \mathrm{yr}^{-1}\right)$ based on SCIAMACHY HCHO columns (Stavrakou et al., 2009b). Even larger reductions are found in the Southeastern US, amounting to ca. 25 and $40 \%$ in the OMI and GOME-2 inversions, respectively (Fig. 13). Anthropogenic and pyrogenic emissions over the US are essentially unchanged by the inversions.

The estimated cumulative June-August US isoprene emissions from both optimizations (7.8 Tg for GOME-2 and 9.5 Tg for OMI) agree well with reported values based on earlier versions of OMI HCHO retrievals $(9.3 \mathrm{Tg}$ according to the variable slope technique as described in Millet et al., 2008). The OMI-based isoprene flux in July 2010, estimated at $3.23 \mathrm{Tg}$, is $30 \%$ lower than the a priori $(4.62 \mathrm{Tg})$, corroborating the low values of the BEIS2 (Biogenic Emissions Inventory System, version 2) inventory (Palmer et al., 2003). 

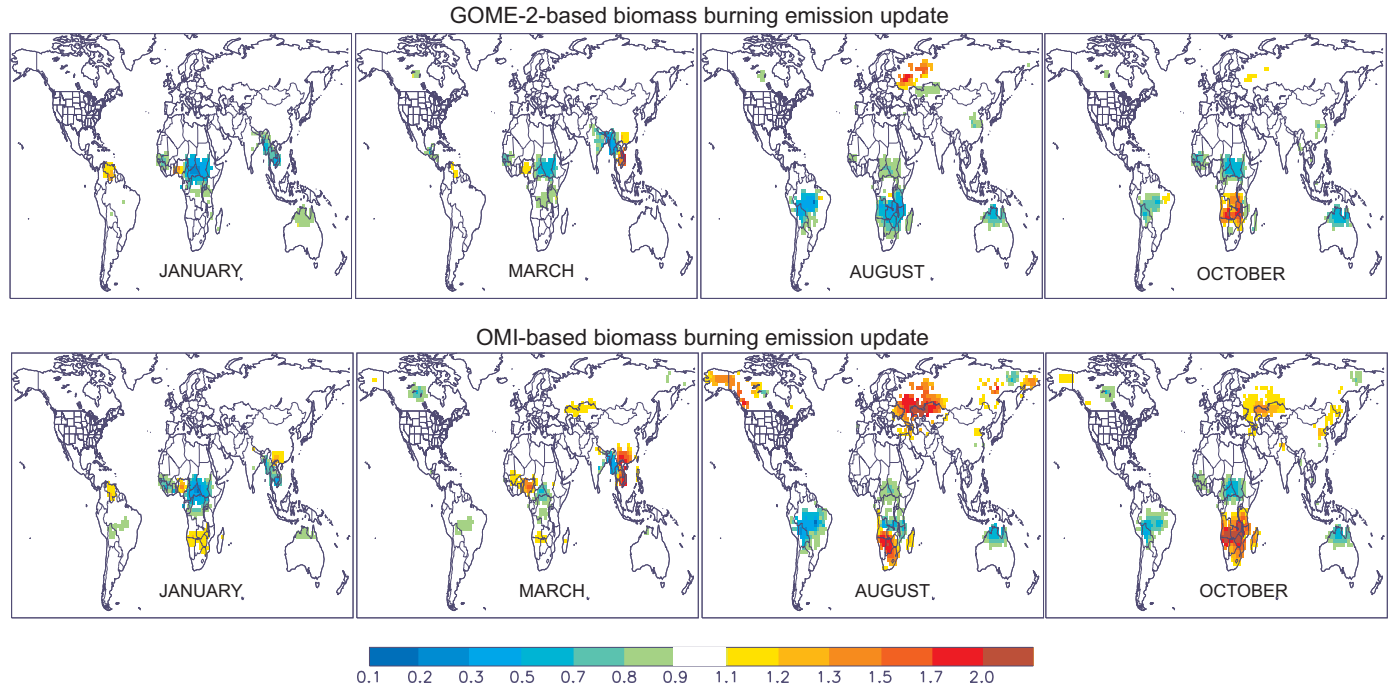

Figure 9. Ratios of optimized to a priori pyrogenic VOC fluxes derived by source inversion of HCHO columns from GOME-2 (upper panels) and OMI (lower panels) in January, March, August and October 2010. Ratio values between 0.9 and 1.1 are not shown for the sake of clarity.

GOME-2-based isoprene emission update

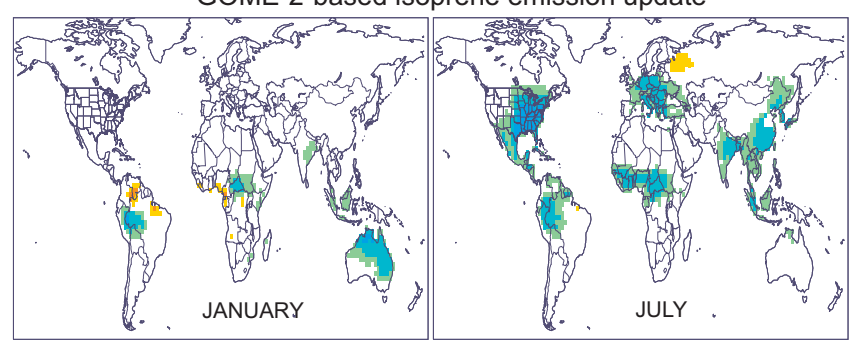

OMI-based isoprene emission update

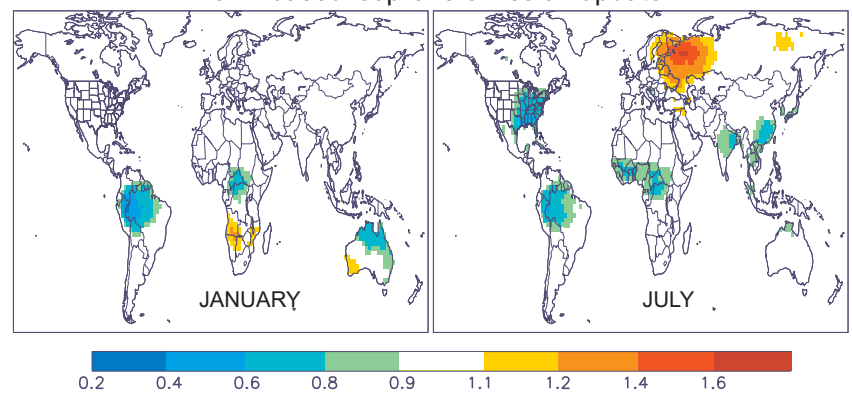

Figure 10. Same as Fig. 9, but for isoprene emissions in January and July.

The model predictions are compared to $\mathrm{HCHO}$ measurements from the INTEX-A aircraft campaign conducted in July-August 2004 over the eastern US (Singh et al., 2006; Fried et al., 2008), shown in Fig. 14. It is worth noting that the measurements by NCAR (National Center for Atmospheric Research) and URI (Univ. Rhode Island) exhibit large differences between them, the NCAR values being ca. $50 \%$ higher than URI values below $2 \mathrm{~km}$ altitude (Fig. 14). The model simulations are performed for 2004, and the concentrations are sampled at the locations and times of the airborne mea-

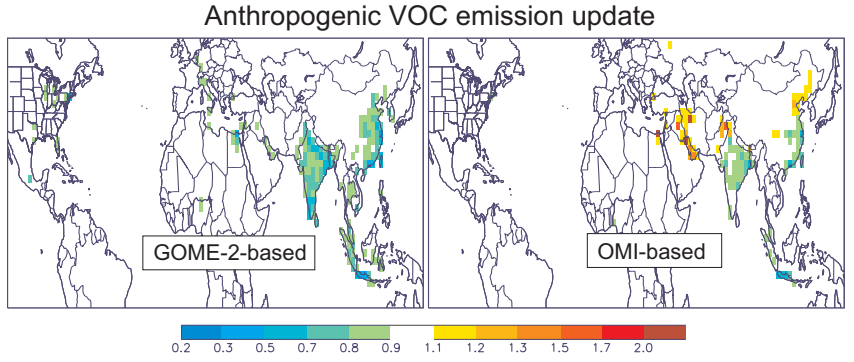

Figure 11. Same as Fig. 9, but for annual anthropogenic VOC fluxes.

surements. In the a posteriori simulation shown in Fig. 14, the bottom-up isoprene emissions for 2004 were multiplied by the isoprene emission update inferred from either the OMI or the GOME-2 inversion for 2010. As seen in Fig. 14, the average $\mathrm{HCHO}$ concentration below $2 \mathrm{~km}$ altitude decreased by about $10 \%$ in the OMI inversion $(15 \%$ in the case of GOME2 ) and remains within the range of the NCAR and URI measurements. Despite the marked underestimation of the modeled HCHO (1.39 and 1.32 ppbv in the OMI and GOME-2 inversions) in comparison to NCAR observations (1.83 ppbv), the emission optimization results in an increased Pearson's spatial correlation coefficient between the modeled and observed concentrations below $2 \mathrm{~km}$, from 0.74 in the a priori to 0.79 and 0.80 in the OMI and GOME-2 inversions. A similar improvement is found with respect to URI data.

\subsection{Russia}

The a priori model underpredicts the observed OMI HCHO columns during the Russian fires of July-August 2010 by up to a factor of 2 , in particular over a broad region extending to 

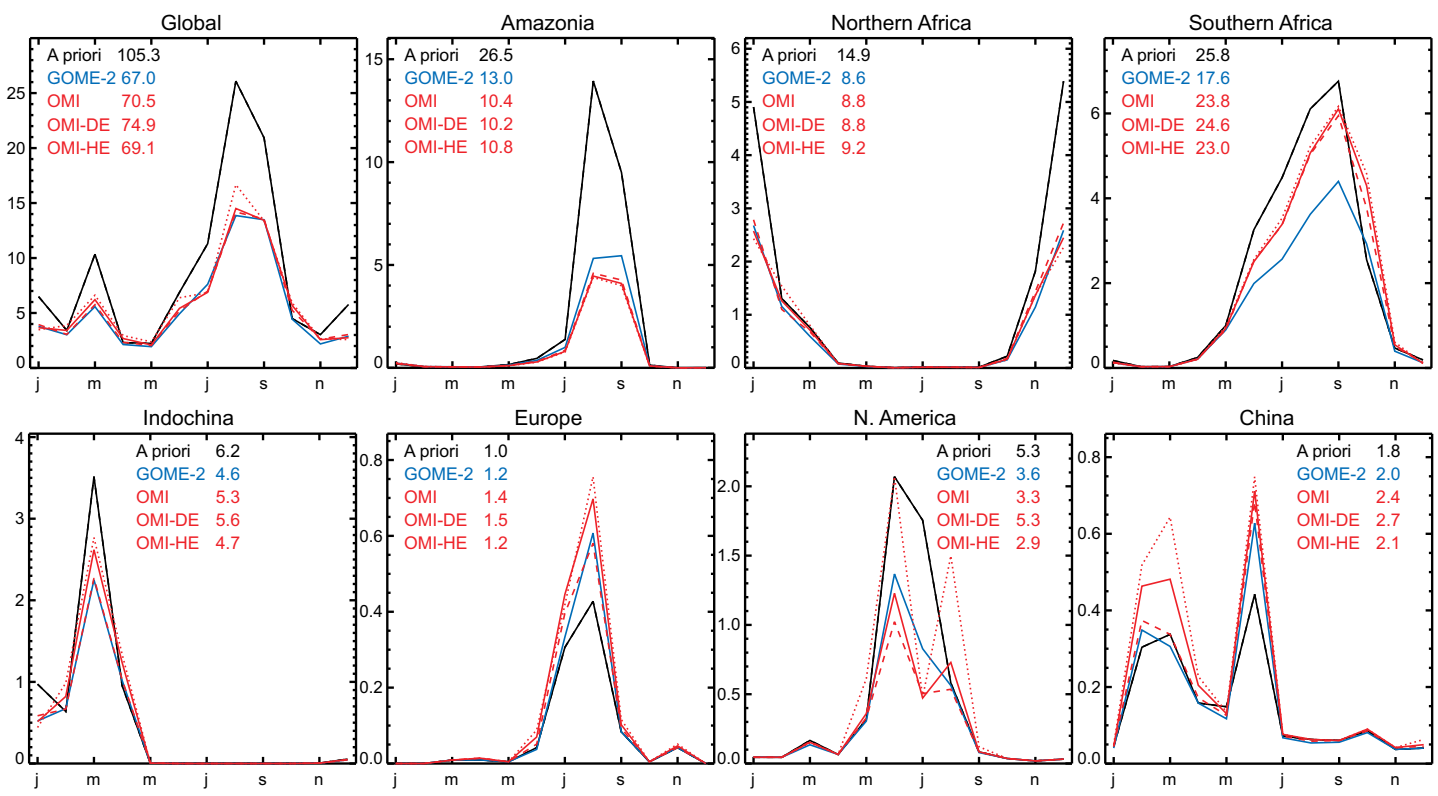

Figure 12. Monthly variation of a priori and top-down biomass burning VOC fluxes for Amazonia $\left(14^{\circ} \mathrm{S}-10^{\circ} \mathrm{N}, 45-80^{\circ} \mathrm{W}\right)$, Africa north and south of the Equator, Indochina $\left(6-22^{\circ} \mathrm{N}, 97.5-110^{\circ} \mathrm{E}\right)$, Europe (including European Russia), N. America (US and Canada), China, and worldwide, expressed in teragrams of VOCs per month. Solid lines are used for the a priori emissions (black), and updated emissions inferred from GOME-2 (blue) and OMI (red) observations. Dotted and dashed red lines are used for the results of the sensitivity studies OMI-DE and OMI-HE (Table 2), respectively. For each inversion, annual fluxes for 2010 (in TgVOC) are given inside the panels.
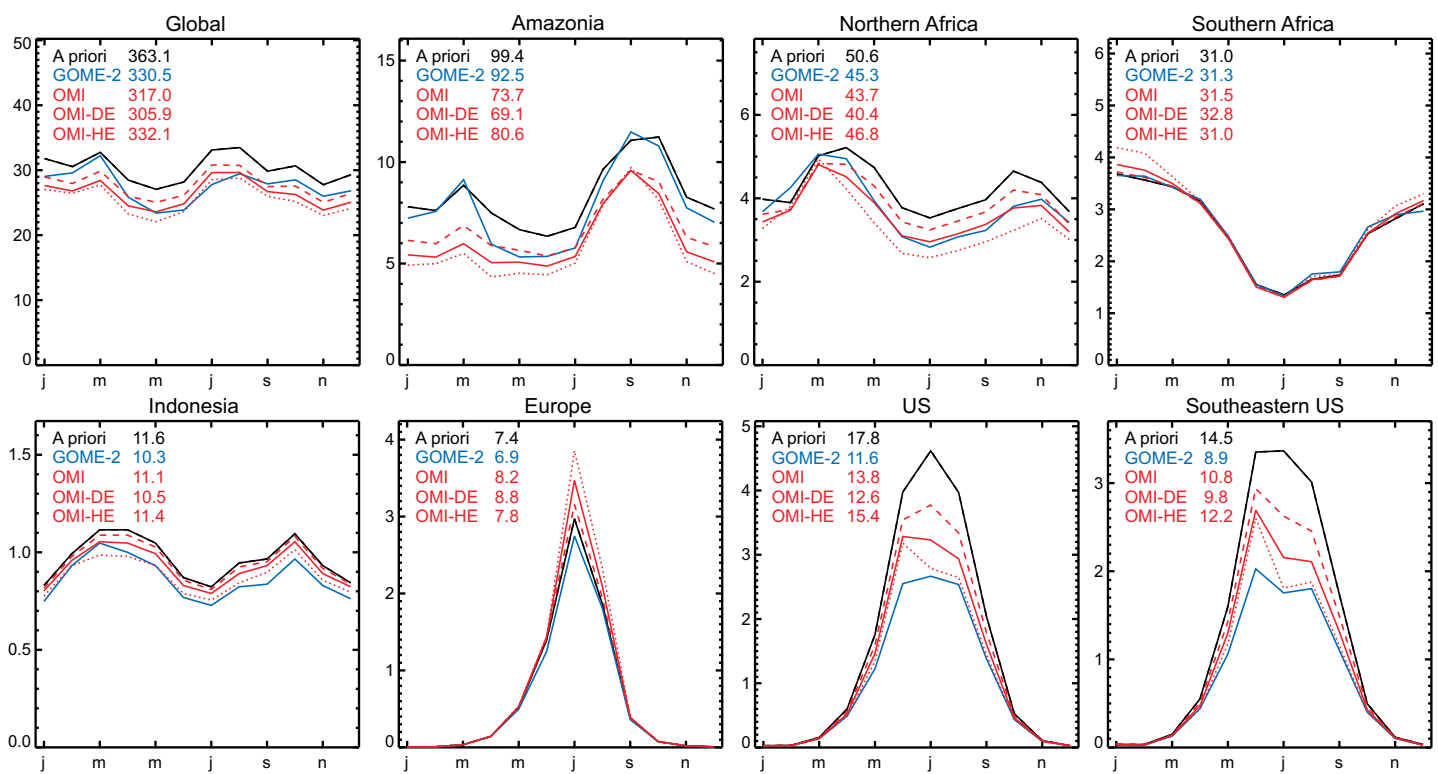

Figure 13. Monthly variation of a priori and satellite-derived isoprene fluxes for Amazonia, Northern and Southern Africa, Europe, N. America (defined as in Fig. 12), Indonesia $\left(10^{\circ} \mathrm{S}-6^{\circ} \mathrm{N}, 95-142.5^{\circ} \mathrm{E}\right)$, and the Southeastern US $\left(25-38^{\circ} \mathrm{N}, 60-100^{\circ} \mathrm{W}\right)$. The color and line code is the same as in Fig. 12. Units are teragrams of isoprene per month. Annual isoprene fluxes per region are given in each panel in teragrams of isoprene.

the north $\left(61^{\circ} \mathrm{N}\right)$ and east $\left(55^{\circ} \mathrm{E}\right)$ of Moscow (Fig. 6, upper panel). Similar spatial patterns are also observed in GOME-2 HCHO columns. However, the GOME-2 columns are lower than OMI over this region, and the model underestimation is less severe, in this case reaching $60 \%$. The lower GOME2 values might be due to the lower retrieval sensitivity of GOME-2 to lower tropospheric HCHO compared to OMI at these latitudes, associated with larger solar zenith angles 


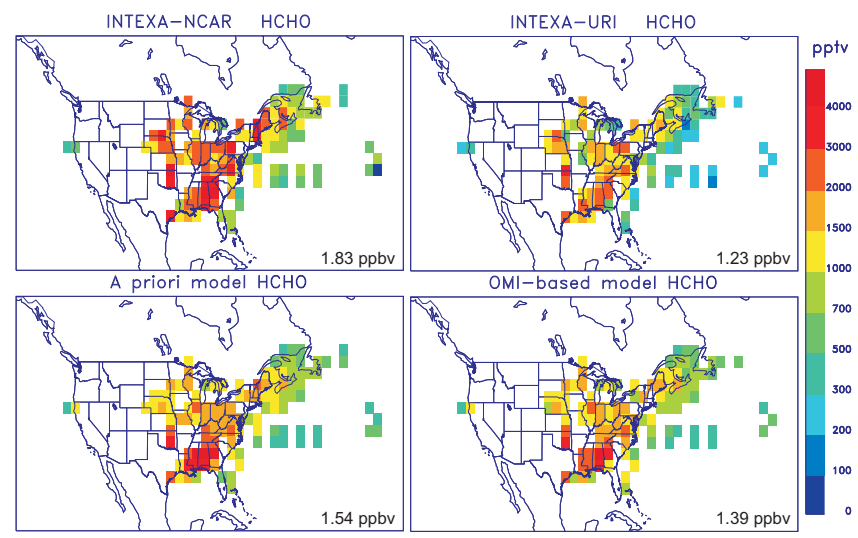

Figure 14. Comparison between $\mathrm{HCHO}$ measurements from the INTEX-A campaign and model concentrations sampled at the measurement times and locations from the a priori simulation and from the OMI-based inversion averaged between the surface and $2 \mathrm{~km}$. The HCHO data are reported from two different instruments, from the National Center for Atmospheric Research (NCAR) and from the University of Rhode Island (URI). The observed and modeled mean HCHO concentrations over the flight domain and altitude range are given inside each panel.

(De Smedt et al., 2015). As a result, the increase of the pyrogenic emission fluxes is strongest in the OMI inversion, from $440 \mathrm{GgVOC}$ in the GFEDv3 inventory to $720 \mathrm{GgVOC}$ (630 GgVOC in GOME-2) in August 2010 over Europe. Accordingly, the isoprene fluxes inferred from the OMI inversion in August are also larger, about $40 \%$ higher than the a priori estimate in the Moscow area, whereas the increase derived by GOME-2 does not exceed $25 \%$. Overall, the OMI data suggest annual isoprene fluxes in Europe are $11 \%$ higher than the a priori inventory (Table 3 ). Note that, although the isoprene enhancement over Russia peaks earlier (July) and at slightly higher latitudes $\left(\mathrm{ca} .61^{\circ} \mathrm{N}\right)$ than the biomass burning emission enhancement $\left(55-57^{\circ} \mathrm{N}\right.$ in August), the significant overlap of the two distributions makes it impossible to rule out that pyrogenic emissions are the only cause for the observed strong formaldehyde columns. The very widespread extent of the observed formaldehyde plume cannot be easily explained by the comparatively much more localized emissions of the GFEDv3 inventory, and an additional, more widespread formaldehyde source (such as isoprene) could help to explain the observations. However, as discussed below, the GFEDv3 total emissions over Russia are likely largely underestimated, and their geographical distribution might also be in error. It is therefore possible that these fires were more widespread than in GFEDv3 and that strong isoprene emission enhancements are not needed to explain the observations.

Strongly enhanced fire emissions in the Moscow region between mid-July and mid-August 2010 were reported based on satellite observations of CO from MOPITT (Measurements Of Pollution In The Troposphere; Konovalov et al.,
2011) and IASI (Krol et al., 2013; R'honi et al., 2013) and on surface measurements (Konovalov et al., 2011). The optimized fire emission inferred by assimilation of IASI CO columns in Krol et al. (2013) lies within 22 and $27 \mathrm{Tg}$ CO during the fires, i.e., about 7-10 times higher than in the bottom-up inventory (GFEDv3). These values are comparable with the ranges of 19-33 and 34-40 Tg CO suggested by R'honi et al. (2013) and Yurganov et al. (2011), respectively, but are much higher than reported values of ca. $10 \mathrm{Tg} \mathrm{CO}$ derived using surface $\mathrm{CO}$ measurements in the Moscow area (Konovalov et al., 2011). The latter study identifies the contribution of peat burning to the total $\mathrm{CO}$ fire emission in this region to be as high as $30 \%$.

The IMAGESv2 a priori CO simulation (using GFEDv3 inventory) underestimates substantially the IASI CO observations. Scaling the $\mathrm{CO}$ emissions in IMAGESv2 to the fire VOC increase suggested by the OMI HCHO optimization, i.e., ca. $60 \%$ in July and August 2010, barely improves the model agreement with the satellite, indicating that, in accordance with earlier studies, more drastic fire flux enhancements (factor of 5-10) are required to reconcile CO modeldata mismatches. The reasons for the differences in the emission increases inferred by $\mathrm{CO}$ and $\mathrm{HCHO}$ during the 2010 Russian fires are currently unknown, but they could be related either to inadequate knowledge of emission factors of $\mathrm{CO}$ and VOCs from peat fires and/or underestimated remotely sensed HCHO columns over fire scenes due to possibly important aerosol effects not accounted for in the retrievals.

\subsection{China}

The dominant emission source in China is anthropogenic and is estimated at $25.5 \mathrm{TgVOC}$ in REASv2 (Kurokawa et al., 2013) for 2008. The biogenic source, mainly located in southern China, amounts to $7 \mathrm{Tg}$ in 2010 in the MEGANMOHYCAN-v2 inventory (Stavrakou et al., 2014; Guenther et al., 2006, 2012). In northern China, the HCHO columns are underestimated by the a priori model in winter compared to OMI, whereas a relatively good agreement is found in summer. In southern China, a general model overestimation is found all year round (Figs. 6, 7).

Although the OMI-based inversion yields total Chinese anthropogenic emissions very similar to the a priori (24.6 TgVOC), the emission patterns are modified with increased emissions in northeastern China and especially around Beijing (20-40\%) and emission reductions in the southeast and in particular around Shanghai (15-47\%) and Guangzhou (15-30\%). The total GOME-2 emission, estimated at $20.6 \mathrm{TgVOC}$, is lower than the OMI result but in good agreement with the estimate (20.2 $\mathrm{Tg}$ in 2008) of the Multi-resolution Emission Inventory for China (MEIC, http://www.meicmodel.org). The flux distributions from both inversions have common features, e.g., decreased fluxes in Shanghai and Guangzhou regions, but contradicting esti- 
mates in the northeast where GOME-2 observations do not support the emission enhancements suggested by OMI.

This discrepancy is primarily due to the lower modeled ratios of 13:30 to 09:30 LT columns (average ratio of 1.0 in the model in northern China between March and November) compared to the satellite data sets (average ratio of 1.16). Note that, however, the model was found to overestimate this ratio against MAX-DOAS data at Beijing and Xianghe (Fig. 5). Another possible cause for the difference between the OMI and GOME-2 results is the limited availability of GOME-2 data in wintertime (Fig. 7) due to the high solar zenith angles leading to large retrieval errors frequently exceeding $100 \%$. For example, GOME-2 columns are unavailable from November to April over Beijing.

In the North China Plain, one of the largest agricultural plains on Earth, the post-wheat-harvest-season fires in June of every year are a common practice for farmers (Huang et al., 2012), and are responsible for poor air quality conditions and environmental harm (Yamaji et al., 2010). Both OMI- and GOME-2-based inversions suggest a considerable enhancement of the agricultural fire flux in this region, by almost a factor of 2 in comparison with the a priori inventory by Huang et al. (2012); cf. Fig. 12. The interannual variability of these emissions will be addressed in a separate work currently in preparation.

Finally, the Chinese isoprene emission are decreased from 7 to $6.5 \mathrm{Tg} \mathrm{yr}^{-1}$ (OMI) and 5.9 $\mathrm{Tg} \mathrm{yr}^{-1}$ (GOME-2), with especially strong decreases in southern China, as illustrated in Fig. 10.

\section{Emissions in the Tropics}

\subsection{South America}

After the 2005 drought in Amazonia, characterized as a onein-a-century event (Marengo et al., 2008), Amazonia suffered a second, even more severe drought in 2010 with major environmental impacts (Marengo et al., 2011). Extensive wildfires broke out in different regions from July to October, with central and southern Amazonia as the main epicenters. The massive fires are reflected in the high HCHO columns (up to

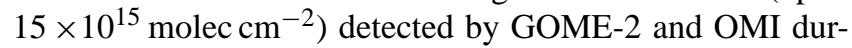
ing these months, about twice the observed columns in the wet season (Fig. 7). Both instruments agree very well on the magnitudes and spatial patterns of the HCHO columns, as illustrated in Fig. 15. The a priori model strongly overestimates the observations during the dry season (by up to $70 \%$ in August), indicating that the GFEDv3 emissions for this region are most likely too high. The GOME-2 and OMI inversions decrease the fire emission by factors of 2 and 2.5, respectively (Fig. 12). Even stronger decreases (factor of 3) are found over northern Bolivia and central Amazonia (Fig. 9).

These emission reductions are supported by comparison with CO columns observed by IASI (George et al., 2009).
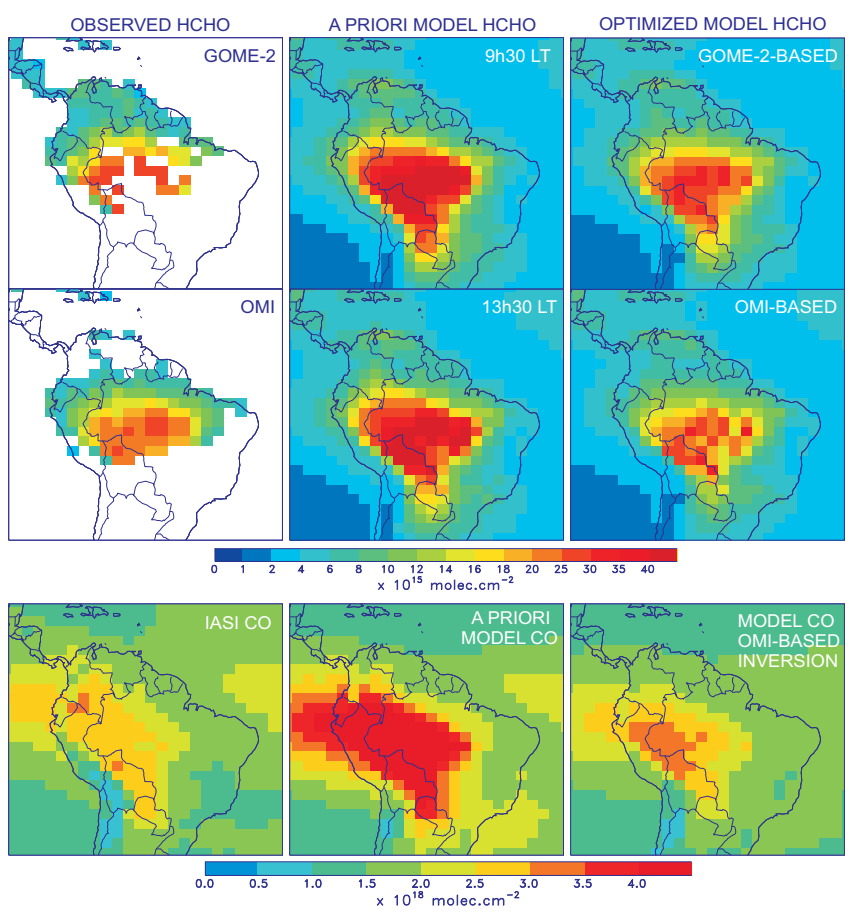

Figure 15. Observed, a priori and a posteriori model $\mathrm{HCHO}$ columns (in $10^{15}$ molec $\mathrm{cm}^{-2}$ ) derived from GOME-2 (upper) and OMI (middle) inversions in Amazonia in August 2010. For the same month, observed CO columns by IASI, a priori model CO columns and $\mathrm{CO}$ columns (in $10^{18}$ molec $\mathrm{cm}^{-2}$ ) from the OMI-based inversion are shown in the bottom panels. CO results from the GOME-2 inversion are very similar to those obtained from OMI and are therefore not shown here.

The use of fire emissions from GFEDv3 leads to strongly overestimated CO columns in comparison to IASI observations in August 2010 (Fig. 15), reaching almost a factor of 2 over western Amazonia. Significant improvement in the model-data match is achieved when the emission reduction inferred by the OMI-based inversion is implemented and applied not only to NMVOCs but also to other compounds including CO. The GFEDv3 emissions of CO in 2010 were also found to be substantially overestimated, by a factor of $\sim 1.8$ over South America between 5 and $25^{\circ} \mathrm{S}$, by inverse modeling of MOPITT CO columns using the GEOS-Chem model (Bloom et al., 2015). The most likely cause for the lower emissions in 2010 compared to 2007 was proposed by these authors to be a reduction of the combusted biomass density possibly due to dry conditions and/or repeat fires. The good consistency found between results using either $\mathrm{CO}$ or $\mathrm{HCHO}$ indicates that the emission factors used in the model for NMVOC and CO (or at least their ratios) are appropriate, unless an error compensation is responsible for the noted good agreement. Note also that, besides the good consistency found between the emission estimates derived from GOME2 and OMI, the performed sensitivity inversions induce only very weak departures from the standard inversion (Fig. 12). 
Isoprene fluxes over Amazonia derived by GOME-2 and OMI inversions are equal to 92.5 and $73.7 \mathrm{Tg}$, respectively. These re 25 and $7 \%$ lower than the prior and in good agreement with previous studies using satellite HCHO observations from the SCIAMACHY instrument (Stavrakou et al., $2009 \mathrm{~b})$. The seasonal variation of the posterior fluxes is consistent with the a priori inventory, except during the transitional wet-to-dry period (April-June) with both GOME-2 and OMI satellite data sets pointing to a significant flux decrease of ca. $25 \%$ (Fig. 13). This behavior confirms previous comparisons using GOME HCHO observations suggesting that factors other than the temperature influence the observed variability (Barkley et al., 2008), such as the growth of new leaves causing a temporary shutdown of the emissions (Barkley et al., 2009).

\subsection{Indonesia}

Fire activity was exceptionally low in 2010, with annual emissions of about $0.1 \mathrm{TgVOC}$, i.e., about 2 orders of magnitude less than for high years such as 2006 according to GFEDv3.

The GOME-2- and OMI-inferred isoprene estimates show good consistency over Indonesia all year round, amounting to 10.3 and $11.1 \mathrm{Tg}$, respectively, and close to the a priori estimate $(11.6 \mathrm{Tg})$. The inferred isoprene emissions are, however, half of the reported fluxes of $25 \mathrm{Tg} \mathrm{yr}^{-1}$ based on SCIAMACHY HCHO observations, which also decreased with respect to their a priori isoprene flux of $35 \mathrm{Tg} \mathrm{yr}^{-1}$ (Stavrakou et al., 2009b). In comparison to that study, the isoprene a priori emissions used in the present work are strongly reduced over this region, due to a drastic reduction by a factor of 4.1 of the MEGANv2.1 basal isoprene rate for tropical rainforests over Asia, as suggested by field measurements in Borneo (Langford et al., 2010). This reduction implemented in the MEGAN-MOHYCAN-v2 model (Stavrakou et al., 2014) is found here to be corroborated by GOME-2 and OMI HCHO measurements.

\subsection{Indochina}

The northern part of the Indochina Peninsula (primarily Myanmar, also Assam in India and parts of Thailand) faces intense forest fires during the dry season, as very well seen in the GOME-2 and OMI HCHO time series, with values reaching $15 \times 10^{15} \mathrm{molec} \mathrm{cm}^{-2}$ in March, about 3 times higher than in the wet season (Fig. 7).

Both the GOME-2 and OMI data point to substantial but very contrasting updates in the pyrogenic fluxes during the fire season (March, Fig. 9): flux reductions by a factor of 2-5 over Myanmar and surrounding forested areas, and flux increases by a factor of almost 2 (or more in the case of OMI) over the southeastern part of the peninsula, which includes Cambodia, southern Laos and southern Vietnam. In the OMI-DE inversion assuming doubled errors on the a pri-

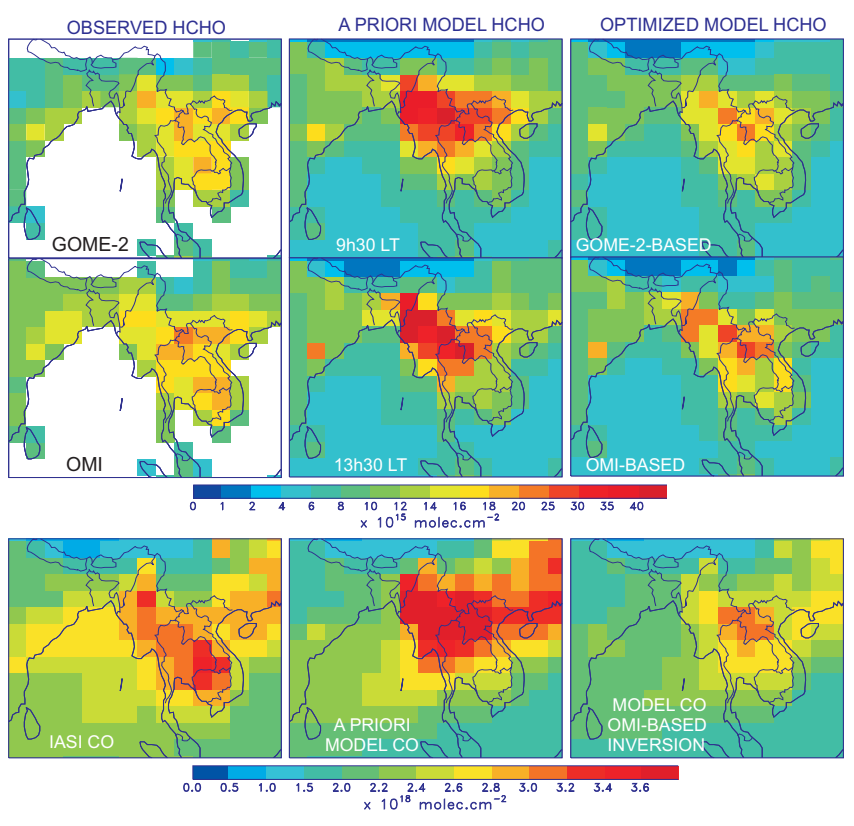

Figure 16. Same as Fig. 15, for the Indochinese Peninsula in March 2010.

ori fluxes, the updates are even more pronounced and reach a factor of 4 over parts of Vietnam and Laos. The annual emissions in the entire region are decreased by 15 and $26 \%$ according to the OMI and GOME-2 inversions, respectively. As illustrated in Fig. 16, the optimization leads to a substantial improvement of the model performance, although the HCHO columns remain significantly underestimated (by up to $20 \%$ ) in the southern part of the peninsula (e.g., Cambodia), most likely due to a too strong underestimation of the GFEDv3 emissions used as a priori in the model. The emission drop over Myanmar and the need for higher emissions in the southeast are partly confirmed by comparisons with IASI CO columns. Indeed, as seen in the lower panel of Fig. 16, modeled $\mathrm{CO}$ simulations using biomass burning fluxes optimized using OMI data (i.e., reduced by ca. $26 \%$ in March relative to GFEDv3) display a better agreement with the observed CO columns, despite an underestimation by $\sim 10 \%$ over most of the peninsula. This result is consistent with the moderate reduction (ca. 20\% in March) of biomass burning emissions of $\mathrm{CO}$ over tropical Asia inferred by Basu et al. (2014) in an inversion based on IASI CO columns utilizing the TM5 (Transport Model 5) atmospheric model with GFEDv3 as a priori inventory.

The strong enhancement of pyrogenic emissions required to comply to the satellite data over the southeastern part of Indochina might be due to the occurrence of agricultural fires in those regions (e.g., Cambodia), known to be a common management practice (Chang and Song, 2010). These fires are very difficult to detect by satellite due to their limited spatial extent. It is worth noting that the latest version of the Fire Inventory from NCAR (FINNv1.5; Wiedinmyer et al., 2011) 
predicts much higher emissions from this region: ca. $43 \mathrm{TgC}$ in March in the region $100-108^{\circ} \mathrm{E}, 10-18^{\circ} \mathrm{N}$, i.e., a factor of 10 higher than in the GFEDv3 inventory $(4.3 \mathrm{TgC})$. The differences between GFEDv3 and FINN are most likely due to inherent differences in the proxy variables used in the respective emission models, burned area in the case of GFEDv3, and active fire counts in the FINN model, both retrieved from MODIS satellite data. The two inventories provide, however, very similar estimates for the more forested, northwestern part of Indochina (19-27 $\left.\mathrm{N}, 97-100^{\circ} \mathrm{E}\right): 105 \mathrm{TgC}$ in GFEDv3, $124 \mathrm{TgC}$ in FINNv1.5.

Considerable cloudiness during the rainy season (MayOctober) causes gaps in the OMI HCHO time series, due to the exclusion of scenes with $\geq 40 \%$ cloud cover. The GOME-2 data series are comparatively less affected by this issue, due to the diurnal precipitation and cloudiness patterns during the monsoon season. Indeed, long-term observations over Indochina (Takahashi et al., 2010) reveal an early afternoon rainfall peak (13:00-16:00 LT) and a heavy rainfall in the early morning (04:00-07:00 LT) but lower precipitation rates between 07:00 and 10:00 LT. GOME-2 observations are therefore less contaminated by clouds and offer a better spatial coverage during the rainy season in this region.

\subsection{Africa}

Over Africa, the annual pyrogenic source, amounting to $40.7 \mathrm{TgVOC}$ in the a priori, is reduced to 26.2 and $32.6 \mathrm{TgVOC}$ in the GOME-2 and OMI inversions, respectively (Table 3). A smaller reduction is also inferred for isoprene fluxes, estimated at $76.6 \mathrm{Tg}$ (GOME-2) and $75.2 \mathrm{Tg}$ (OMI), within $10 \%$ of the a priori value $(81.6 \mathrm{Tg}$ ). These estimates are in line with recently reported isoprene fluxes over Africa based on the NASA data set of OMI HCHO columns ( $77 \mathrm{TgC}$ or $87 \mathrm{Tg}$ isoprene compared to $116 \mathrm{Tg}$ isoprene in the a priori reported fluxes, Marais et al., 2012). The spatial distribution of the emission updates is displayed in Figs. 9, 10 and 11.

African fire occurrence peaks in central Africa (e.g., the Democratic Republic of the Congo or DRC) in early June (Fig. 7) and lasts until August with the end of the dry season. The GOME-2 and OMI observations show an excellent accordance, with morning columns being about $10 \%$ higher than in the afternoon, consistent with measurements in Bujumbura (Fig. 5), although the morning to afternoon ratio was found to be higher in the ground-based observations (1.25). The model simulations overpredict the observations of both sounders during the fire season by 10 $25 \%$. The posterior bias reduction (cf. Fig. 7, DRC region) is achieved by a significant biomass burning flux decrease, reaching a factor of 2 in the southern part of DRC, and 20$30 \%$ elsewhere between 2 and $12^{\circ} \mathrm{S}$. In a similar manner, up to a factor of 2 in emissions decrease is also needed in the region of the central African republic during the fire season (November-February) to match the observed columns
(Fig. 7), in good agreement with our previous study using SCIAMACHY HCHO columns (Stavrakou et al., 2009b). Only small changes are inferred for isoprene emissions in Northern Africa, with $11 \%$ (GOME-2) and $16 \%$ (OMI) decrease compared to the a priori emissions, as illustrated in Fig. 13.

In Southern Africa, biogenic fluxes are highest in January and lowest in July, while the fire season starts in May and peaks in September (Figs. 12 and 13). Both GOME-2 and OMI inversions infer only small isoprene flux updates (Table 3). Regarding fire emissions, in contrast with GOME2 data suggesting a ca. $30 \%$ flux reduction (to 17.6 from $25.8 \mathrm{TgVOC}$ ), the OMI-based estimate lies within $10 \%$ of the a priori, due to a compensation of flux decreases north of approximately $15^{\circ} \mathrm{S}$, and flux increases in the southernmost part of the continent, south of ca. $15^{\circ} \mathrm{S}$ (Fig. 9). Although the seasonal patterns are essentially preserved by the optimization, both inversions predict higher emissions at the end of the dry season, especially over Zambia and surrounding regions (October; Figs. 9, 12). These updates are highest (factor of $\sim 2$ ) in the OMI optimization, but the patterns are very similar in both inversions.

\section{Conclusions}

The emissions of NMVOCs in 2010 were optimized by inverse modeling using the IMAGESv2 CTM and its adjoint with HCHO column abundances from either GOME-2 or OMI as observational constraint. Given their different overpass times, the consistency of the inferred emissions depends on how the model can faithfully reproduce the diurnal cycle of HCHO columns. The modeled diurnal cycle displays a great variability mirroring the competing influences of photochemical productions and losses as well as the diurnal profiles of emissions and (to a lesser extent) meteorological parameters. Where anthropogenic VOCs are dominant, daytime photochemical production and the anthropogenic emission profile lead to an early afternoon maximum, in agreement with MAX-DOAS observations in Belgium, Holland and (during summertime) the Beijing area. Over oceanic areas, where methane oxidation is the only significant source in the model, a similar behavior is also simulated, in agreement with FTIR data at Reunion Island. The poor model performance at several locations (Bujumbura, OHP, Beijing in winter/spring) is likely at least partly due to the coarse model resolution, as shown by the very different diurnal profiles observed at Beijing and Xianghe. This limited representativity of local ground-based sites possibly explains (part of) the large deviations (typically $\pm 10-30 \%$ ) found between the calculated and observed ratios of the $\mathrm{HCHO}$ columns at 13:30 and 09:30 LT. Despite this large scatter, the average ratio of 13:30 LT columns to 09:30 LT columns is only slightly higher (1.126) in the model compared to the MAX-DOAS and FTIR measurements (1.043). 
Unfortunately, no ground-based measurements are available in regions where the simulated diurnal cycle amplitude is largest, namely over intense fire scenes at both tropical and boreal latitudes. Over these regions, an evening maximum is predicted, and the peak to trough ratio reaches up to $70 \%$. In isoprene-rich areas, the diurnal $\mathrm{HCHO}$ cycle often, but not always, displays a minimum around noon, when the photochemical sink is highest, and a maximum in the late evening or early morning, in agreement with a previous modeling study (Barkley et al., 2011). Validation studies over forested areas will be needed to determine how realistic these patterns are.

The ratio of 13:30 to 09:30 LT columns is most often between 0.8 and 1.2 according to ground-based measurements. Similar but generally higher values of this ratio are calculated by the model, $8 \%$ higher on average. The satellite, on the other hand, although in qualitative agreement with the above, suggests higher ratios of 13:30 to 09:30 LT columns than the model at mid-latitudes, whereas no clear pattern emerges in tropical regions (Fig. 7). Nevertheless, these discrepancies in terms of morning/afternoon ratios are most often small in comparison with the model-data differences in the HCHO columns themselves. As a consequence, the emission fluxes inferred from both GOME-2 and OMI inversions are found to be generally very consistent. They both suggest a strong decrease of the global biomass burning source, by about $35 \%$. The decrease is mostly concentrated in the Tropics, e.g., over Amazonia (factor of $>2$ reduction), over equatorial Africa and over Myanmar and the surrounding regions (factor of 2-5 reduction in March). These updates are confirmed by comparing $\mathrm{CO}$ columns predicted by the model using the biomass burning emissions estimated by the OMI inversion with IASI CO columns. The results are also consistent with a recent study using MOPITT CO columns (Bloom et al., 2015). The seasonal profile of the emissions is generally well preserved by the inversions, except for a significant enhancement near the end of the dry season, in particular over Southern Africa (in October) but also Amazonia (in September) and Indochina (in April). Both satellite data sets point to strong enhancements of agricultural fire fluxes in the North China Plain in June (factor of almost 2) and in the southern part of Indochina, compared to the a priori estimate.

Very good agreement between the inversion results is found for isoprene fluxes, with global annual fluxes reduced by $9 \%$ (GOME-2) and $13 \%$ (OMI) compared to the a priori $363 \mathrm{Tg}$. In the Southeastern US, both inversions agree on a substantial decrease by ca. $25 \%$ (OMI) and $40 \%$ (GOME-2), in good agreement with previous estimates based on SCIAMACHY and OMI HCHO data. This reduction improves the correlation between calculated and observed $\mathrm{HCHO}$ concentrations during the airborne INTEX-A campaign conducted over the eastern US. Over Amazonia, the source of isoprene is consistently lower than the prior, in particular during the wet-to-dry season transition (April-June), in accordance with previously reported estimates. Over Indonesia, the optimizations do not present significant deviations from the prior, thereby validating the a priori isoprene inventory which incorporated decreased basal emission rates for Asian tropical rainforests.

The results show that the global anthropogenic VOC fluxes are not well constrained, as indicated by the negligible updates derived by the inversions over most areas, except over highly polluted regions with a distinct anthropogenic signal in the HCHO columns, like China. In this region, the changes in the emission patterns found by the OMI-based optimization are not well reproduced by the inversion of GOME-2 data, likely reflecting discrepancies in the 13:30 to 09:30 LT columns ratio calculated by the model. In spite of those discrepancies, our study demonstrates that a high degree of compatibility is achieved between top-down pyrogenic and biogenic emissions derived by GOME-2 and OMI HCHO data, while the flux estimates are found to be weakly dependent on changes in key uncertain parameters in the performed sensitivity inversions.

This study identifies several important large regions where the differences between bottom-up and top-down estimates are particularly important and the inferred flux estimates from both satellites show a high degree of consistency, like the Amazon and the Southeastern US. Recent airborne field measurements in those regions should provide additional constraints and help close the gap between bottom-up and top-down estimates. The increasing availability of in situ observations of formaldehyde and related trace gases can provide a basis for improving and assessing model simulations of diurnal variations over a range of environmental conditions and interactions between biogenic and anthropogenic compounds (e.g., DiGangi et al., 2012). Furthermore, planned geostationary satellites have the potential to improve satellite-based emission estimates by characterizing diurnal variations in atmospheric constituents (Saide et al., 2014). Finally, new cross-section measurements of isoprene in the infrared open new avenues for the detection of isoprene using satellites (e.g., IASI) and a direct link to isoprene emissions (Brauer et al., 2014).

\section{The Supplement related to this article is available online at doi:10.5194/acp-15-11861-2015-supplement.}

Acknowledgements. This research was supported by the Belgian Science Policy Office through the PRODEX projects ACROSAT and IASI.Flow (2014-2015) and by the European Space Agency (ESA) through the GlobEmission project (2011-2016). P.-F. Coheur is senior research associate with FRS-FNRS. The authors would like to thank the two anonymous reviewers for their careful reading and constructive criticism.

Edited by: C. H. Song 


\section{References}

Andreae, M. O. and Merlet, P.: Emission of trace gases and aerosols from biomass burning, Global Biogeochem. Cy., 15, 955-966, doi:10.1029/2000GB001382, 2001.

Arneth, A., Schurgers, G., Lathière, J., Duhl, T., Beerling, D. J., Hewitt, C. N., Martin, M., and Guenther, A.: Global terrestrial isoprene emission models: sensitivity to variability in climate and vegetation, Atmos. Chem. Phys., 11, 8037-8052, doi:10.5194/acp-11-8037-2011, 2011.

Barkley, M. P., Palmer, P. I., Kuhn, U., Kesselmeier, J., Chance, K., Kurosu, T. P., Martin, R. V., Helmig, D., and Guenther, A.: Net ecosystem fluxes of isoprene over tropical South America inferred from Global Ozone Monitoring Experiment (GOME) observations of HCHO columns, J. Geophys. Res., 113, D20304, doi:10.1029/2008JD009863, 2008.

Barkley, M. P., Palmer, P. I., De Smedt, I., Karl, T., Guenther, A., and Van Roozendael, M.: Regulated large-scale annual shutdown of Amazonian isoprene emissions?, Geophys. Res. Lett., 36, L04803, doi:10.1029/2008GL036843, 2009.

Barkley, M. P., Palmer, P. I., Ganzeveld, L., Arneth, A., Hagberg, D., Karl, T., Guenther, A., Paulot, F., Wennberg, P. O., Mao, J., Kurosu, T. P., Chance, K., Müller, J.-F., De Smedt, I., Van Roozendael, M., Chen, D., Wang, Y., and Yantosca, R. M.: Can a "state of the art" chemistry transport model simulate Amazonian tropospheric chemistry?, J. Geophys. Res., 116, D16302, doi:10.1029/2011JD015893, 2011.

Barkley, M. P., De Smedt, I., Van Roozendael, M., Kurosu, T. P., Chance, K., Arneth, A., Hagberg, D., Guenther, A., Paulot, F., Marais, E., and Mao, J.: Top-down isoprene emissions over tropical South America inferred from SCIAMACHY and OMI formaldehyde columns, J. Geophys. Res. Atmos., 118, 68496868, doi:10.1002/jgrd.50552, 2013.

Basu, S., Krol, M., Butz, A., Clerbaux, C., Sawa, Y., Machida, T., Matsueda, H., Frankenberg, C., Hasekamp, O. P., and Aben, I.: The seasonal variation of the $\mathrm{CO}_{2}$ flux over Tropical Asia estimated from GOSAT, CONTRAIL, and IASI, Geophys. Res. Lett., 41, 1809-1815, 2014.

Bloom, A. A., Worden, J., Jiang, Z., Worden, H., Kurosu, T., Frankenberg, C., and Schimel, D.: Remote sensing constraints on South America fire traits by Bayesian fusion of atmospheric and surface data, Geophys. Res. Lett., 42, 1268-1274, doi:10.1002/2014GL062584, 2015.

Bloss, C., Wagner, V., Bonzanini, A., Jenkin, M. E., Wirtz, K., Martin-Reviejo, M., and Pilling, M. J.: Evaluation of detailed aromatic mechanisms (MCMv3 and MCMv3.1) against environmental chamber data, Atmos. Chem. Phys., 5, 623-639, doi:10.5194/acp-5-623-2005, 2005.

Boersma, K. F., Eskes, H. J., Dirksen, R. J., van der A, R. J., Veefkind, J. P., Stammes, P., Huijnen, V., Kleipool, Q. L., Sneep, M., Claas, J., Leitão, J., Richter, A., Zhou, Y., and Brunner, D.: An improved tropospheric $\mathrm{NO}_{2}$ column retrieval algorithm for the Ozone Monitoring Instrument, Atmos. Meas. Tech., 4, 19051928, doi:10.5194/amt-4-1905-2011, 2011.

Brauer, C. S., Blake, T. A., Guenther, A. B., Sharpe, S. W., Sams, R. L., and Johnson, T. J.: Quantitative infrared absorption cross sections of isoprene for atmospheric measurements, Atmos. Meas. Tech., 7, 3839-3847, doi:10.5194/amt-7-3839-2014, 2014.

Chance, K., Palmer, P. I., Spurr, R. J. D., Martin, R. V., Kurosu, T., and Jacob, D. J.: Satellite observations of formaldehyde over
North America from GOME, Geophys. Res. Lett., 27, 34613464, 2000.

Chang, D. and Song, Y.: Estimates of biomass burning emissions in tropical Asia based on satellite-derived data, Atmos. Chem. Phys., 10, 2335-2351, doi:10.5194/acp-10-2335-2010, 2010.

Choi, W., Faloona, I. C., Bouvier-Brown, N. C., McKay, M., Goldstein, A. H., Mao, J., Brune, W. H., LaFranchi, B. W., Cohen, R. C., Wolfe, G. M., Thornton, J. A., Sonnenfroh, D. M., and Millet, D. B.: Observations of elevated formaldehyde over a forest canopy suggest missing sources from rapid oxidation of arboreal hydrocarbons, Atmos. Chem. Phys., 10, 8761-8781, doi:10.5194/acp-10-8761-2010, 2010.

Crounse, J. D., Paulot, F., Kjaergaard, J. G., and Wennberg, P. O.: Peroxy radical isomerization in the oxidation of isoprene, Phys. Chem. Chem. Phys., 13, 13607-13613, 2011.

Damian, V., Sandu, A., Damian, M., Potra, F., and Carmichael, G. R.: The Kinetic PreProcessor KPP - A Software Environment for Solving Chemical Kinetics, Comput. Chem. Eng., 26, 15671579, 2002.

De Smedt, I., Müller, J.-F., Stavrakou, T., van der A, R., Eskes, H., and Van Roozendael, M.: Twelve years of global observations of formaldehyde in the troposphere using GOME and SCIAMACHY sensors, Atmos. Chem. Phys., 8, 4947-4963, doi:10.5194/acp-8-4947-2008, 2008.

De Smedt, I., Van Roozendael, M., Stavrakou, T., Müller, J.-F., Lerot, C., Theys, N., Valks, P., Hao, N., and van der A, R.: Improved retrieval of global tropospheric formaldehyde columns from GOME-2/MetOp-A addressing noise reduction and instrumental degradation issues, Atmos. Meas. Tech., 5, 2933-2949, doi:10.5194/amt-5-2933-2012, 2012.

De Smedt, I., Stavrakou, T., Hendrick, F., Danckaert, T., Vlemmix, T., Pinardi, G., Theys, N., Lerot, C., Gielen, C., Vigouroux, C., Hermans, C., Fayt, C., Veefkind, P., Müller, J.-F., and Van Roozendael, M.: Diurnal, seasonal and long-term variations of global formaldehyde columns inferred from combined OMI and GOME-2 observations, Atmos. Chem. Phys. Discuss., 15, 12241-12300, doi:10.5194/acpd-15-12241-2015, 2015.

DiGangi, J. P., Henry, S. B., Kammrath, A., Boyle, E. S., Kaser, L., Schnitzhofer, R., Graus, M., Turnipseed, A., Park, J-H., Weber, R. J., Hornbrook, R. S., Cantrell, C. A., Maudlin III, R. L., Kim, S., Nakashima, Y., Wolfe, G. M., Kajii, Y., Apel, E.C., Goldstein, A. H., Guenther, A., Karl, T., Hansel, A., and Keutsch, F. N.: Observations of glyoxal and formaldehyde as metrics for the anthropogenic impact on rural photochemistry, Atmos. Chem. Phys., 12, 9529-9543, doi:10.5194/acp-12-9529-2012, 2012.

Dufour, G., Wittrock, F., Camredon, M., Beekmann, M., Richter, A., Aumont, B., and Burrows, J. P.: SCIAMACHY formaldehyde observations: constraint for isoprene emission estimates over Europe?, Atmos. Chem. Phys., 9, 1647-1664, doi:10.5194/acp-91647-2009, 2009.

Fried, A., Walega, J. G., Olson, J. R., Crawford, J. H., Chen, G., Weibring, P., Richter, D., Roller, C., Tittel, F., Heikes, B. G., Snow, J. A., Shen, H., O'Sullivan, D. W., Porter, M. J., Fuelberg, H. E., Halland, J. J., and Millet, D. B.: Formaldehyde over North America and the North Atlantic during the summer 2004 INTEX campaign : Methods, observed distributions and measurement comparisons, J. Geophys. Res., 113, D10302, doi:10.1029/2007JD009185, 2008. 
Fu, T.-M., Jacob, D. J., Palmer, P. I., Chance, K., Wang, Y. X., Barletta, B., Blake, D. R., Stanton, J. C., and Pilling, M. J.: Space-based formaldehyde measurements as constraints on volatile organic compound emissions in east and south Asia and implications for ozone, J. Geophys. Res., 112, D06312, doi:10.1029/2006JD007853, 2007.

George, M., Clerbaux, C., Hurtmans, D., Turquety, S., Coheur, P.F., Pommier, M., Hadji-Lazaro, J., Edwards, D. P., Worden, H., Luo, M., Rinsland, C., and McMillan, W.: Carbon monoxide distributions from the IASI/METOP mission: evaluation with other space-borne remote sensors, Atmos. Chem. Phys., 9, 8317-8330, doi:10.5194/acp-9-8317-2009, 2009.

Gielen, C., Van Roozendael, M., Hendrick, F., Pinardi, G., Vlemmix, T., De Bock, V., De Backer, H., Fayt, C., Hermans, C., Gillotay, D., and Wang, P.: A simple and versatile cloudscreening method for MAX-DOAS retrievals, Atmos. Meas. Tech., 7, 3509-3527, doi:10.5194/amt-7-3509-2014, 2014.

Gilbert, J.-C. and Lemaréchal, C.: Some numerical experiments with variable storage quasi-Newton algorithms, Math. Program., 45, 407-435, 1989.

González Abad, G., Liu, X., Chance, K., Wang, H., Kurosu, T. P., and Suleiman, R.: Updated Smithsonian Astrophysical Observatory Ozone Monitoring Instrument (SAO OMI) formaldehyde retrieval, Atmos. Meas. Tech., 8, 19-32, doi:10.5194/amt-8-192015, 2015.

Goodwin, J. W. L., Salway, A. G., Murrells, T. P., Dore, C. J., Passant, N. R., King, K. R., Coleman, P. J., Hobson, M. M., Pye, S. T., Watterson, J. D.: UK Emissions of air pollutants 1970-1999, National Atmospheric Emissions Inventory Report, AEAT/ENV/R/0798, ISBN 1-85580-031 4, available at: http://uk-air.defra.gov.uk/reports/empire/naei/annreport/ annrep99/appdx6.pdf (last access: 22 October 2015), 2001.

Griffiths, P. R. and de Haseth, J. A.: Fourier Transform Infrared Spectrometry, John Wiley \& Sons, Inc., Hoboke, New Jersey, USA, 2007.

Guenther, A., Karl, T., Harley, P., Wiedinmyer, C., Palmer, P. I., and Geron, C.: Estimates of global terrestrial isoprene emissions using MEGAN (Model of Emissions of Gases and Aerosols from Nature), Atmos. Chem. Phys., 6, 3181-3210, doi:10.5194/acp-63181-2006, 2006.

Guenther, A. B., Jiang, X., Heald, C. L., Sakulyanontvittaya, T., Duhl, T., Emmons, L. K., and Wang, X.: The Model of Emissions of Gases and Aerosols from Nature version 2.1 (MEGAN2.1): an extended and updated framework for modeling biogenic emissions, Geosci. Model Dev., 5, 1471-1492, doi:10.5194/gmd-51471-2012, 2012.

Hendrick, F., Müller, J.-F., Clémer, K., Wang, P., De Mazière, M., Fayt, C., Gielen, C., Hermans, C., Ma, J. Z., Pinardi, G., Stavrakou, T., Vlemmix, T., and Van Roozendael, M.: Four years of ground-based MAX-DOAS observations of HONO and $\mathrm{NO}_{2}$ in the Beijing area, Atmos. Chem. Phys., 14, 765-781, doi:10.5194/acp-14-765-2014, 2014.

Hewson, W., Bösch, H., Barkley, M. P., and De Smedt, I.: Characterisation of GOME-2 formaldehyde retrieval sensitivity, Atmos. Meas. Tech., 6, 371-386, doi:10.5194/amt-6-371-2013, 2013.

Hönninger, G., von Friedeburg, C., and Platt, U.: Multi axis differential optical absorption spectroscopy (MAX-DOAS), Atmos. Chem. Phys., 4, 231-254, doi:10.5194/acp-4-231-2004, 2004
Huang, X., Xi, M., Li, J., and Song, Y.: A high-resolution emission inveotry of crop burning in fields in China based on MODIS thermal anomalies/fire products, Atmos. Environ., 50, 9-15, 2012.

Jenkin, M. E., Murrels, T. P., and Passant, N. R.: The temporal dependence of ozone precursor emissions: estimation and application, AEA Technology, Report No. AEAT/R/ENV/0355 Issue 1, Abingdon, Oxfordshire, UK, 2000.

Junkermann, W.: On the distribution of formaldehyde in the western Po-Valley, Italy, during FORMAT 2002/2003, Atmos. Chem. Phys., 9, 9187-9196, doi:10.5194/acp-9-9187-2009, 2009.

Kleipool, Q. L., Dobber, M. R., de Haan, J. F., and Levelt, P. F.: Earth surface reflectance climatology from 3 years of OMI data, J. Geophys. Res., 113, D18308, doi:10.1029/2008JD010290, 2008.

Konovalov, I. B., Beekmann, M., Kuznetsova, I. N., Yurova, A., and Zvyagintsev, A. M.: Atmospheric impacts of the 2010 Russian wildfires: integrating modelling and measurements of an extreme air pollution episode in the Moscow region, Atmos. Chem. Phys., 11, 10031-10056, doi:10.5194/acp-11-10031-2011, 2011.

Krol, M., Peters, W., Hooghiemstra, P., George, M., Clerbaux, C., Hurtmans, D., McInerney, D., Sedano, F., Bergamaschi, P., El Hajj, M., Kaiser, J. W., Fisher, D., Yershov, V., and Muller, J.-P.: How much CO was emitted by the 2010 fires around Moscow?, Atmos. Chem. Phys., 13, 4737-4747, doi:10.5194/acp-13-47372013, 2013.

Kurokawa, J., Ohara, T., Morikawa, T., Hanayama, S., JanssensMaenhout, G., Fukui, T., Kawashima, K., and Akimoto, H.: Emissions of air pollutants and greenhouse gases over Asian regions during 2000-2008: Regional Emission inventory in ASia (REAS) version 2, Atmos. Chem. Phys., 13, 11019-11058, doi:10.5194/acp-13-11019-2013, 2013.

Langford, B., Misztal, P. K., Nemitz, E., Davison, B., Helfter, C., Pugh, T. A. M., MacKenzie, A. R., Lim, S. F., and Hewitt, C. N.: Fluxes and concentrations of volatile organic compounds from a South-East Asian tropical rainforest, Atmos. Chem. Phys., 10, 8391-8412, doi:10.5194/acp-10-8391-2010, 2010.

Logan, J. A., Prather, M. J., Wofsy, S. C., and McElroy, M. B.: Tropospheric chemistry: A global perspective, J. Geophys. Res., 86, 7210-7254, 1981.

MacDonald, S. M., Oetjen, H., Mahajan, A. S., Whalley, L. K., Edwards, P. M., Heard, D. E., Jones, C. E., and Plane, J. M. C.: DOAS measurements of formaldehyde and glyoxal above a south-east Asian tropical rainforest, Atmos. Chem. Phys., 12, 5949-5962, doi:10.5194/acp-12-5949-2012, 2012.

Marais, E. A., Jacob, D. J., Kurosu, T. P., Chance, K., Murphy, J. G., Reeves, C., Mills, G., Casadio, S., Millet, D. B., Barkley, M. P., Paulot, F., and Mao, J.: Isoprene emissions in Africa inferred from OMI observations of formaldehyde columns, Atmos. Chem. Phys., 12, 6219-6235, doi:10.5194/acp-12-62192012, 2012.

Marais, E. A., Jacob, D. J., Guenther, A., Chance, K., Kurosu, T. P., Murphy, J. G., Reeves, C. E., and Pye, H. O. T.: Improved model of isoprene emissions in Africa using Ozone Monitoring Instrument (OMI) satellite observations of formaldehyde: implications for oxidants and particulate matter, Atmos. Chem. Phys., 14, 7693-7703, doi:10.5194/acp-14-7693-2014, 2014.

Marengo, J. A., Nobre, C., Tomasella, J., Oyama, M., Sampaio de Oliveira, G., de Oliveira, R., Camargo, H., Alves, L., and Brown, 
I. F.: The Drought of Amazonia in 2005, J. Climate, 21, 495-516, doi:10.1175/2007JCLI1600.1, 2008.

Marengo, J. A., Tomasella, J., Alves, L. M., Soares, W. R., and Rodriguez, D. A.: The drought of 2010 in the context of historical droughts in the Amazon region, Geophys. Res. Lett., 38, L12703, doi:10.1029/2011GL047436, 2011.

Martin, R. V, Chance, K. V., Jacob, D. J., Kurosu, T. P., Spurr, R. J. D., Bucsela, E. J., Gleason, J., Palmer, P. I., Bey, I., Fiore, A. M., Li, Q., Yantosca, R. M., and Koelemeijer, R. B. A.: An improved retrieval of tropospheric nitrogen dioxide from GOME, J. Geophys. Res., 107, 4437, doi:10.1029/2001JD001027, 2002.

Millet, D. B., Jacob, D. J., Turquety, S., Hudman, R. C., Wu, S., Fried, A., Walega, J., Heikes, B. G., Blake, D. R., Singh, H. B., Anderson, B. E., and Clarke, A. D.: Formaldehyde distribution over North America: Implications for satellite retrievals of formaldehyde columns and isoprene emission, J. Geophys. Res., 111, D24S02, doi:10.1029/2005JD006853, 2006.

Millet, D. B., Jacob, D. J., Boersma, K. F., Fu, T., Kurosu, T. P., Chance, K., Heald, C. L., and Guenther, A.: Spatial distribution of isoprene emissions from North America derived from formaldehyde columns measurements by the OMI satellite sensor, J. Geophys. Res., 113, D02307, doi:10.1029/2007JD008950, 2008.

Millet, D. B., Guenther, A., Siegel, D. A., Nelson, N. B., Singh, H. B., de Gouw, J. A., Warneke, C., Williams, J., Eerdekens, G., Sinha, V., Karl, T., Flocke, F., Apel, E., Riemer, D. D., Palmer, P. I., and Barkley, M.: Global atmospheric budget of acetaldehyde: 3-D model analysis and constraints from in-situ and satellite observations, Atmos. Chem. Phys., 10, 3405-3425, doi:10.5194/acp-10-3405-2010, 2010.

Mu, M., Randerson, J. T., van der Werf, G. R., Giglio, L., Kasibhatla, P., Morton, D., Collatz, G. J., DeFries, R. S., Hyer, E. J., Prins, E. M., Griffith, D. W. T., Wunch, D., Toon, G. C., Sherlock, V., and Wennberg, P. O.: Daily and 3-hourly variability in global fire emissions and consequences for atmospheric model predictions of carbon monoxide, J. Geophys. Res., 116, D24303, doi:10.1029/2011JD016245, 2011.

Müller, J.-F. and Brasseur, G.: IMAGES: A three-dimensional chemical transport model of the global troposphere, J. Geophys. Res., 100, 16445-16490, 1995.

Müller, J.-F. and Stavrakou, T.: Inversion of $\mathrm{CO}$ and $\mathrm{NO}_{x}$ emissions using the adjoint of the IMAGES model, Atmos. Chem. Phys., 5, 1157-1186, doi:10.5194/acp-5-1157-2005, 2005.

Müller, J.-F., Stavrakou, T., Wallens, S., De Smedt, I., Van Roozendael, M., Potosnak, M. J., Rinne, J., Munger, B., Goldstein, A., and Guenther, A. B.: Global isoprene emissions estimated using MEGAN, ECMWF analyses and a detailed canopy environment model, Atmos. Chem. Phys., 8, 1329-1341, doi:10.5194/acp-81329-2008, 2008.

Palmer, P. I., Jacob, D. J., Fiore, A., Martin, R. V., Chance, K. V., Kurosu, T. P., Bey, I., and Yantosca, R.: Air mass factor formulation for spectroscopic measurements from satellites: Application to formaldehyde retrievals from the Global Ozone Monitoring Experiment, J. Geophys. Res., 106, 14539-14550, doi:10.1029/2000JD900772, 2001.

Palmer, P. I., Jacob, D. J., Fiore, A., Chance, K. V., Martin, R. V., Kurosu, T. P., Bey, I., Yantosca, R., Fiore, A., and Li, Q.: Mapping isoprene emissions over North America using formaldehyde column observations from space, J. Geophys. Res., 108, 4180, doi:10.1029/2002JD002153, 2003.

Palmer, P. I., Abbot, D. S., Fu, T.-M., Jacob, D. J., Chance, K., Kurosu, T. P., Guenther, A., Wiedinmyer, C., Stanton, J. C., Pilling, M. J., Pressley, S. N., Lamb, B., and Sumner, A. L.: Quantifying the seasonal and interannual variability of North American isoprene emissions using satellite observations of the formaldehyde column, J. Geophys. Res. 111, D12315, doi:10.1029/2005JD006689, 2006.

Peeters, J. and Müller, J.-F.: $\mathrm{HO}_{x}$ radical regeneration in isoprene oxidation via peroxy radical isomerisations. II: Experimental evidence and global impact, Phys. Chem. Chem. Phys., 12, 14227 14235, doi:10.1039/C0CP00811G, 2010.

Peeters, J., Nguyen, T. L., and Vereecken, L.: $\mathrm{HO}_{x}$ radical regeneration in the oxidation of isoprene, Phys. Chem. Chem. Phys., 11, 5935-5939, 2009.

Peeters, J., Müller, J.-F., Stavrakou, T., and Nguyen, S. V.: Hydroxyl radical recycling in isoprene oxidation driven by hydrogen bonding and hydrogen tunneling: the upgraded LIM1 mechanism, J. Phys. Chem. A, 118, 8625-8643, doi:10.1021/jp5033146, 2014.

Pinardi, G., Van Roozendael, M., Abuhassan, N., Adams, C., Cede, A., Clémer, K., Fayt, C., Frieß, U., Gil, M., Herman, J., Hermans, C., Hendrick, F., Irie, H., Merlaud, A., Navarro Comas, M., Peters, E., Piters, A. J. M., Puentedura, O., Richter, A., Schönhardt, A., Shaiganfar, R., Spinei, E., Strong, K., Takashima, H., Vrekoussis, M., Wagner, T., Wittrock, F., and Yilmaz, S.: MAXDOAS formaldehyde slant column measurements during CINDI: intercomparison and analysis improvement, Atmos. Meas. Tech., 6, 167-185, doi:10.5194/amt-6-167-2013, 2013.

Platt, U. and Stutz, J.: Differential Absorption Spectroscopy, Physics of Earth and Space Environments, Springer-Verlag Berlin, Heidelberg, Germany, doi:10.1007/978-3-540-75776-4, 2008.

R'Honi, Y., Clarisse, L., Clerbaux, C., Hurtmans, D., Duflot, V., Turquety, S., Ngadi, Y., and Coheur, P.-F.: Exceptional emissions of $\mathrm{NH}_{3}$ and $\mathrm{HCOOH}$ in the 2010 Russian wildfires, Atmos. Chem. Phys., 13, 4171-4181, doi:10.5194/acp-13-41712013, 2013.

Richter, A., Begoin, M., Hilboll, A., and Burrows, J. P.: An improved $\mathrm{NO}_{2}$ retrieval for the GOME-2 satellite instrument, Atmos. Meas. Tech., 4, 1147-1159, doi:10.5194/amt-4-1147-2011, 2011.

Roberts, G., Wooster, M. J., and Lagoudakis, E.: Annual and diurnal african biomass burning temporal dynamics, Biogeosciences, 6 , 849-866, doi:10.5194/bg-6-849-2009, 2009.

Saide, P. E., Kim, J., Song, C. H., Choi, M., Cheng, Y., and Carmichael, G. R.: Assimilation of next generation geostationary aerosol optical depth retrievals to improve air quality simulations, Geophys. Res. Lett., 41, 9188-9196, doi:10.1002/2014GL062089, 2014.

Sander, S. P., Abbatt, J., Barker, J. R., Burkholder, J. B., Friedl, R. R., Golden, D. M., Huie, R. E., Kolb, C. E., Kurylo, M. J., Moortgat, G. K., Orkin, V. L., and Wine, P. H.: Chemical Kinetics and Photochemical Data for Use in Atmospheric Studies, Evaluation No. 17, JPL Publication 10-6, Jet Propulsion Laboratory, Pasadena, USA, http://jpldataeval.jpl.nasa.gov (last access: 22 October 2015), 2011.

Saunders, S. M., Jenkin, M. E., Derwent, R. G., and Pilling, M. J.: Protocol for the development of the Master Chemical Mech- 
anism, MCM v3 (Part A): tropospheric degradation of nonaromatic volatile organic compounds, Atmos. Chem. Phys., 3, 161-180, doi:10.5194/acp-3-161-2003, 2003.

Schultz, M. G., Heil, A., Hoelzemann, J. J., Spessa, A., Thonicke, K., Goldammer, J., Held, A. C., and Pereira, J. M.: Global Emissions from Wildland Fires from 1960 to 2000, Global Biogeochem. Cy., 22, GB2002, doi:10.1029/2007GB003031, 2008.

Singh, H. B., Brune, W. H., Crawford, J. H., Jacob, D. J., and Russell, P. B.: Overview of the summer 2004 Intercontinental Chemical Transport Experiment North America (INTEX-A), J. Geophys. Res., 111, D24S01, doi:10.1029/2006JD007905, 2006.

Sofiev, M., Ermakova, T., and Vankevich, R.: Evaluation of the smoke-injection height from wild-land fires using remote-sensing data, Atmos. Chem. Phys., 12, 1995-2006, doi:10.5194/acp-12-1995-2012, 2012.

Sofiev, M., Vankevich, R., Ermakova, T., and Hakkarainen, J.: Global mapping of maximum emission heights and resulting vertical profiles of wildfire emissions, Atmos. Chem. Phys., 13, 7039-7052, doi:10.5194/acp-13-7039-2013, 2013.

Spurr, R. J. D.: LIDORT and VLIDORT: Linearized pseudospherical scalar and vector discrete ordinate radiative transfer models for use in remote sensing retrieval problems, in: Light Scattering Reviews, edited by: Kokhanovsky, A., Berlin, Germany, 229-271, 2008.

Stammes, P., Sneep, M., de Haan, J. F., Veefkind, J. P., Wang, P., and Levelt, P. F.: Effective cloud fractions from the Ozone Monitoring Instrument: Theoretical framework and validation, J. Geophys. Res., 113, D16S38, doi:10.1029/2007JD008820, 2008.

Stavrakou, T., Müller, J.-F., De Smedt, I., Van Roozendael, M., van der Werf, G. R., Giglio, L., and Guenther, A.: Evaluating the performance of pyrogenic and biogenic emission inventories against one decade of space-based formaldehyde columns, Atmos. Chem. Phys., 9, 1037-1060, doi:10.5194/acp-9-1037-2009, 2009a.

Stavrakou, T., Müller, J.-F., De Smedt, I., Van Roozendael, M., van der Werf, G. R., Giglio, L., and Guenther, A.: Global emissions of non-methane hydrocarbons deduced from SCIAMACHY formaldehyde columns through 2003-2006, Atmos. Chem. Phys., 9, 3663-3679, doi:10.5194/acp-9-3663-2009, 2009b.

Stavrakou, T., Müller, J.-F., De Smedt, I., Van Roozendael, M., Kanakidou, M., Vrekoussis, M., Wittrock, F., Richter, A., and Burrows, J. P.: The continental source of glyoxal estimated by the synergistic use of spaceborne measurements and inverse modelling, Atmos. Chem. Phys., 9, 8431-8446, doi:10.5194/acp-98431-2009, 2009c

Stavrakou, T., Peeters, J., and Müller, J.-F.: Improved global modelling of HOx recycling in isoprene oxidation: evaluation against the GABRIEL and INTEX-A aircraft campaign measurements, Atmos. Chem. Phys., 10, 9863-9878, doi:10.5194/acp-10-98632010, 2010

Stavrakou, T., Guenther, A., Razavi, A., Clarisse, L., Clerbaux, C., Coheur, P.-F., Hurtmans, D., Karagulian, F., De Mazière, M., Vigouroux, C., Amelynck, C., Schoon, N., Laffineur, Q., Heinesch, B., Aubinet, M., Rinsland, C., and Müller, J.-F.: First space-based derivation of the global atmospheric methanol emission fluxes, Atmos. Chem. Phys., 11, 4873-4898, doi:10.5194/acp-11-4873-2011, 2011.

Stavrakou, T., Müller, J.-F., Boersma, K. F., van der A, R. J., Kurokawa, J., Ohara, T., and Zhang, Q.: Key chemical $\mathrm{NO}_{x}$ sink uncertainties and how they influence top-down emissions of nitrogen oxides, Atmos. Chem. Phys., 13, 9057-9082, doi:10.5194/acp-13-9057-2013, 2013.

Stavrakou, T., Müller, J.-F., Bauwens, M., De Smedt, I., Van Roozendael, M., Guenther, A., Wild, M., and Xia, X.: Isoprene emissions over Asia 1979-2012: impact of climate and land-use changes, Atmos. Chem. Phys., 14, 4587-4605, doi:10.5194/acp14-4587-2014, 2014

Takahashi, H. G., Fujinami, H., Yasunari, T., and Matsumoto, J.: Diurnal rainfall pattern observed by Tropical Rainfall Measuring Mission Precipitation Radar (TRMM-PR) around the Indochina peninsula, J. Geophys. Res., 115, D07109, doi:10.1029/2009JD012155, 2010

Valks, P., Pinardi, G., Richter, A., Lambert, J.-C., Hao, N., Loyola, D., Van Roozendael, M., and Emmadi, S.: Operational total and tropospheric $\mathrm{NO}_{2}$ column retrieval for GOME-2, Atmos. Meas. Tech., 4, 1491-1514, doi:10.5194/amt-4-1491-2011, 2011.

van der Werf, G. R., Randerson, J. T., Giglio, L., Collatz, G. J., Mu, M., Kasibhatla, P. S., Morton, D. C., DeFries, R. S., Jin, Y., and van Leeuwen, T. T.: Global fire emissions and the contribution of deforestation, savanna, forest, agricultural, and peat fires (19972009), Atmos. Chem. Phys., 10, 11707-11735, doi:10.5194/acp10-11707-2010, 2010.

Vigouroux, C., Hendrick, F., Stavrakou, T., Dils, B., De Smedt, I., Hermans, C., Merlaud, A., Scolas, F., Senten, C., Vanhaelewyn, G., Fally, S., Carleer, M., Metzger, J.-M., Müller, J.-F., Van Roozendael, M., and De Mazière, M.: Ground-based FTIR and MAX-DOAS observations of formaldehyde at Réunion Island and comparisons with satellite and model data, Atmos. Chem. Phys., 9, 9523-9544, doi:10.5194/acp-9-9523-2009, 2009.

Vlemmix, T., Hendrick, F., Pinardi, G., De Smedt, I., Fayt, C., Hermans, C., Piters, A., Wang, P., Levelt, P., and Van Roozendael, M.: MAX-DOAS observations of aerosols, formaldehyde and nitrogen dioxide in the Beijing area: comparison of two profile retrieval approaches, Atmos. Meas. Tech., 8, 941-963, doi:10.5194/amt-8-941-2015, 2015.

Wang, P., Stammes, P., van der A, R., Pinardi, G., and van Roozendael, M.: FRESCO+: an improved $\mathrm{O}_{2}$ A-band cloud retrieval algorithm for tropospheric trace gas retrievals, Atmos. Chem. Phys., 8, 6565-6576, doi:10.5194/acp-8-6565-2008, 2008.

Wiedinmyer, C., Akagi, S. K., Yokelson, R. J., Emmons, L. K., AlSaadi, J. A., Orlando, J. J., and Soja, A. J.: The Fire INventory from NCAR (FINN): a high resolution global model to estimate the emissions from open burning, Geosci. Model Dev., 4, 625641, doi:10.5194/gmd-4-625-2011, 2011.

Yamaji, K., Li, J., Uno, I., Kanaya, Y., Irie, H., Takigawa, M., Komazaki, Y., Pochanart, P., Liu, Y., Tanimoto, H., Ohara, T., Yan, X., Wang, Z., and Akimoto, H.: Impact of open crop residual burning on air quality over Central Eastern China during the Mount Tai Experiment 2006 (MTX2006), Atmos. Chem. Phys., 10, 7353-7368, doi:10.5194/acp-10-7353-2010, 2010.

Yurganov, L. N., Rakitin, V., Dzhola, A., August, T., Fokeeva, E., George, M., Gorchakov, G., Grechko, E., Hannon, S., Karpov, A., Ott, L., Semutnikova, E., Shumsky, R., and Strow, L.: Satellite- and ground-based CO total column observations over 2010 Russian fires: accuracy of top-down estimates based on thermal IR satellite data, Atmos. Chem. Phys., 11, 7925-7942, doi:10.5194/acp-11-7925-2011, 2011. 
Zhu, L., Jacob, D. J., Mickley, L. J., Marais, E. A., Cohan, D. S., Yoshida, Y., Duncan, B. N., González Abad, G., and Chance, K. V.: Anthropogenic emissions of highly reactive volatile organic compounds in eastern Texas inferred from oversampling of satellite (OMI) measurements of HCHO columns, Environ. Res. Lett., 9, 114004, doi:10.1088/1748-9326/9/11/114004, 2014. 